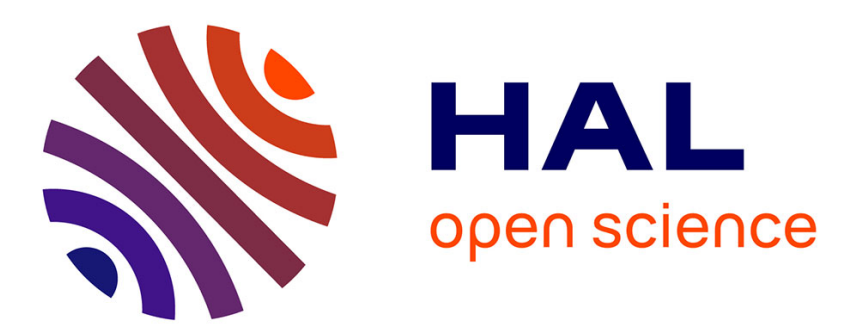

\title{
A methodological framework for Eco-Industrial Park design and optimization
}

E. Kuznetsova, Enrico Zio, R Farel

\section{To cite this version:}

E. Kuznetsova, Enrico Zio, R Farel. A methodological framework for Eco-Industrial Park design and optimization. Journal of Cleaner Production, 2016, 126, 10.1016/j.jclepro.2016.03.025 . hal01338162

\section{HAL Id: hal-01338162 \\ https://hal.science/hal-01338162}

Submitted on 28 Jun 2016

HAL is a multi-disciplinary open access archive for the deposit and dissemination of scientific research documents, whether they are published or not. The documents may come from teaching and research institutions in France or abroad, or from public or private research centers.
L'archive ouverte pluridisciplinaire HAL, est destinée au dépôt et à la diffusion de documents scientifiques de niveau recherche, publiés ou non, émanant des établissements d'enseignement et de recherche français ou étrangers, des laboratoires publics ou privés. 


\title{
Manuscript contains 13763 words
}

\section{A methodological framework for Eco-Industrial Park design and optimization}

\author{
E. Kuznetsova ${ }^{1}$ \& E. Zio ${ }^{1,2}$, R. Farel $^{3}$
}

${ }^{1}$ Chair on Systems Science and the Energetic Challenge, Fondation EDF, CentraleSupélec, Université Paris-Saclay, Grande Voie des Vignes, 92290 Chatenay-Malabry, France

${ }^{2}$ Dipartimento di Energia, Politecnico di Milano, Milano, Italy

${ }^{3}$ Paris Saclay Energy Efficiency (PS2E), Research and Education Institute, Les Loges-enJosas, France

\begin{abstract}
An Eco-Industrial Park (EIP) is composed of a number of Industrial Symbiosis (IS) instances, which allow energy/material exchanges among the different industrial enterprises (Individual Actors, IA) therein. By so doing, IA's economic and environmental performances can be improved. Despite recent methodological advancements, the existing approaches to EIP design optimization are still suffering from several major problems: (i) dominance of the global EIP optimum over the local IA optimum, (ii) limited number of optimization objectives falling into the categories of economic and environmental objectives and (iii) EIP optimization performed without considering possible operational uncertainties. In addition, the adoption of the bio-inspired concept of IS makes EIP evolve from classical engineered systems towards complex engineered systems, with associated static and dynamic complexity characteristics.
\end{abstract}

To highlight and understand the complexity features of EIP, in this paper we present them as intelligent networks for multiple energy and material exchanges, drawing a parallel with another typical complex system, that of the electric power network, in its modern Smart Grid (SG) concept, conceived to improve and optimize the distribution and use of electrical energy.

Then, the modelling and optimization framework proposed in this paper adopts a more systematic methodology for accounting of the EIP complexity characteristics and addressing the associated optimization challenges. The proposed approach allows ensuring a sustainable and robust EIP design, thanks to the due account given to the related uncertainties and risks, e.g., due to major changes in the regulatory context and IA operational strategies, failures of interconnections among IA, interruption or shutdown of IA operation.

Keywords: Circular Economy, Eco-industrial Park, Industrial Symbiosis, industrial interconnected system, complex system, modelling and optimization under uncertainty.

\section{Introduction}

Industry requires and consumes considerable amounts of energy and materials for transformation of raw materials into end products. It accounts for much of energy consumption (200 quadrillion British thermal units (Btu) or about 38\% of the total energy consumption in 2010 (EIA 2013)). Due to the increase of production capacities in existing plants and the installation of new industrial units, this energy consumption continues to rise together with industrial emissions. These latter are typically quantified in terms of GHG emissions, and an increase of 30\% has been observed between 2000 and 2010 (IPCC 2014). 
Utilization of natural resources, like water, is also significant in the industrial sector, with world consumption estimated to rise of $22 \%$ by 2025 (UN 2003).

To address the above challenges for a sustainable industry, different measures can be integrated into the industrial systems for a more rational energy and material resources utilization, and environmental impact decrease. According to the OECD report 'EcoInnovation in Industry: Enabling Green Growth' industrial eco-innovations can successfully address climate change and realise the "green growth" by means of breakthrough innovative solutions (e.g., technological, economic, social etc.) (OECD 2010). One area in which such industrial eco-innovations are sought is the energy and material management in industrial areas. The overarching idea is to interconnect industrial systems into industrial 'food chains' that strengthens the material and energy metabolism (Wen \& Meng 2014) following the principles of Circular Economy (CE) (Pearce \& Turner 1990), e.g., decrease energy and material consumption, create added value for the industrial waste and decrease environmental pollution (Table 1). Materials and energy flows ${ }^{1}$ exchanges can be obtained within industrial parks composed of a set of different industrial enterprises located in the same geographical area, e.g., a city or region (Gu, Yassine, et al. 2013), and connected through networks for materials and energy exchange (Figure 1). The symbiotic relationships in the EIP give the opportunity to gain collective EIP benefits significantly larger than the sum of the individual benefits of each of the industrial enterprises (Chertow 2004). However, the industrial systems interconnecting into an EIP leads to more complex engineered systems, whose design and operation require appropriate methodologies capable of going beyond classical energy/material processes integration, to capture, address and solve the different structural and behavioural challenges which emerge. In order to address this requirement, there is no solution but to formulate the problem in a design perspective, define the concept, and clarify the methodological approach.

In this respect, the questions of how to design an EIP includes but not limited to the engineering optimization (e.g., for a heat network) and the economic trade-off (e.g., investment repartition).The intention is to raise the discussion at a more systematic level, building on and extending the few examples of successful EIP development, such as those in Kalundborg or Ulsan, which are 'customized' developments, where each techno-economical solution was programmed to be successful for the specific, respective context. By analogy with the concept of Smart Grids (SG) for electric power transmission and distribution, which are intended to operate distributed generation sources and intelligently connect them to electricity consumers, this paper proposes a modelling and optimization framework for the design of the complex industrial interconnected systems of EIP. To ensure a sustainable and robust EIP design, due account is given to uncertainties and risks, e.g., due to major changes in the regulatory context and IA operational strategies, failures of interconnections among IA, interruption or shutdown of IA operation.

The paper propounds an optimization methodology for support to the decision maker, i.e., local authority, industrial park operator or a group of IA, during EIP deployment process.

\footnotetext{
${ }^{1}$ Energy flows include flows of electrical, thermal, chemical or other types of energies. Thus, besides the "classical" energy flows, such as electricity or steam, hydrogen for fast conversion from chemical to electrical energy and vice versa can be, for example, also considered. Material flows include flows that are not energycarriers, such as cold water.
} 
However, the optimize managerial and collaboration practices among EIP stakeholders for EIP deployment do not enter the scope of this paper. The final goal of the paper is to propose a methodological framework for EIP modelling and optimization, taking into account EIP specificities in terms of complexity characteristics and the Industrial Symbiosis (IS) concept. The methodological framework stands on abstract modelling and an optimization procedure.

Table 1. Examples and characteristics of some successful EIP.

\begin{tabular}{|c|c|c|c|c|c|c|c|c|c|}
\hline \multirow[t]{2}{*}{ EIP } & \multirow{2}{*}{$\begin{array}{l}\text { Approach } \\
\& \text { period }^{(1)} \\
\text { of } \\
\text { deployment }\end{array}$} & \multicolumn{3}{|c|}{ Economic indicators } & \multicolumn{5}{|c|}{ Environmental benefits } \\
\hline & & $\begin{array}{l}\text { Total } \\
\text { investment }\end{array}$ & Profit & $\begin{array}{l}\text { Average } \\
\text { payback } \\
\text { period }\end{array}$ & $\begin{array}{l}\text { Energy } \\
\text { savings }\end{array}$ & $\begin{array}{l}\text { Water } \\
\text { savings }\end{array}$ & $\begin{array}{l}\text { Waste } \\
\text { reduction }\end{array}$ & $\begin{array}{l}\mathrm{CO}_{2} \\
\text { reduction }\end{array}$ & $\begin{array}{l}\text { Air } \\
\text { pollution } \\
\text { reduction }\end{array}$ \\
\hline $\begin{array}{l}\text { Ulsan, South } \\
\text { Korea (Behera } \\
\text { et al. 2012): } \\
13 \text { symbiosis, } \\
41 \text { actors }\end{array}$ & $\begin{array}{l}\text { Top-down } \\
2 \quad \text { years } \\
\text { (symbiotic } \\
\text { projects } \\
\text { officially } \\
\text { launched in } \\
2005 \text { ) }\end{array}$ & $\begin{array}{lr}\begin{array}{r}\text { \$ } 64.93 \\
\text { (including }\end{array} & \text { M } \\
1.9 \quad M & \text { for } \\
\text { R\&D) } & \end{array}$ & $\begin{array}{l}\$ 68.52 \\
\text { M/year } \\
(3)\end{array}$ & 0.84 year & NA & NA & NA & $\begin{array}{l}227,363 \\
\text { ton/year }\end{array}$ & $\begin{array}{l}3682.2 \\
\text { ton/year }\end{array}$ \\
\hline $\begin{array}{l}\text { Kwinana, } \\
\text { Australia } \\
\text { (Beers \& } \\
\text { Biswas 2008; } \\
\text { KIC 2008): } \\
47 \quad \text { symbiosis, } \\
37 \text { actors }\end{array}$ & $\begin{array}{l}\text { Mixed } \\
\text { Continuous } \\
\text { deployment } \\
\text { since } 1991\end{array}$ & $\begin{array}{l}\text { NA (including } \\
\text { around } \$ \\
700,000 \text { for } \\
\mathrm{R} \& \mathrm{D} \text { and } \\
\text { environmental } \\
\text { monitoring) }\end{array}$ & NA & NA & $\begin{array}{l}1,042 \\
\text { GWh/year }\end{array}$ & $\begin{array}{l}2,166 \\
\text { Ggal/year }\end{array}$ & $\begin{array}{l}421,600 \\
\text { ton/year }\end{array}$ & $\begin{array}{l}\text { "equivalent } \\
\text { of } \\
\text { removing } \\
73,000 \text { cars } \\
\text { from the } \\
\text { road" }\end{array}$ & $\begin{array}{l}134,999 \\
\text { metric } \\
\text { ton/year }\end{array}$ \\
\hline $\begin{array}{l}\text { Kalundborg, } \\
\text { Denmark } \\
\text { (Chertow 2013; } \\
\text { Domenech \& } \\
\text { Davies 2011): } \\
19 \text { symbiosis, } 9 \\
\text { actors }\end{array}$ & $\begin{array}{l}\text { Bottom-up } \\
\text { Continuous } \\
\text { deployment } \\
\text { since } 1961\end{array}$ & $\$ 78.5 \mathrm{M}$ & $\begin{array}{l}\$ 15 \\
\text { M/year }\end{array}$ & NA & NA & $\begin{array}{l}1108.8 \\
\text { Mgal/year } \\
\text { (ground } \\
\text { and } \\
\text { surface } \\
\text { water) }\end{array}$ & NA & $\begin{array}{l}240,000 \\
\text { ton/year }\end{array}$ & $\begin{array}{l}\text { Around } \\
70,000 \\
\text { ton/year of } \\
\text { fly ash and } \\
2,800 \\
\text { ton/year of } \\
\text { sulphur }\end{array}$ \\
\hline
\end{tabular}

${ }^{(1)}$ Deployment approaches: (i) spontaneous (bottom-up), when the symbiotic relationships arise naturally among enterprises based on their long-term neighbourhood, (ii) planned (top-down), when the industrial park and the synergies (interactions) between the enterprises within are designed with the specific purpose to constitute the EIP and (iii) mixed both bottom-up and top-down.

(2) Total research, negotiation and deployment period.

(3) Profit is the summation of both supplier and recipient.

${ }^{(4)}$ Paybacks periods for different symbioses have been identified. 


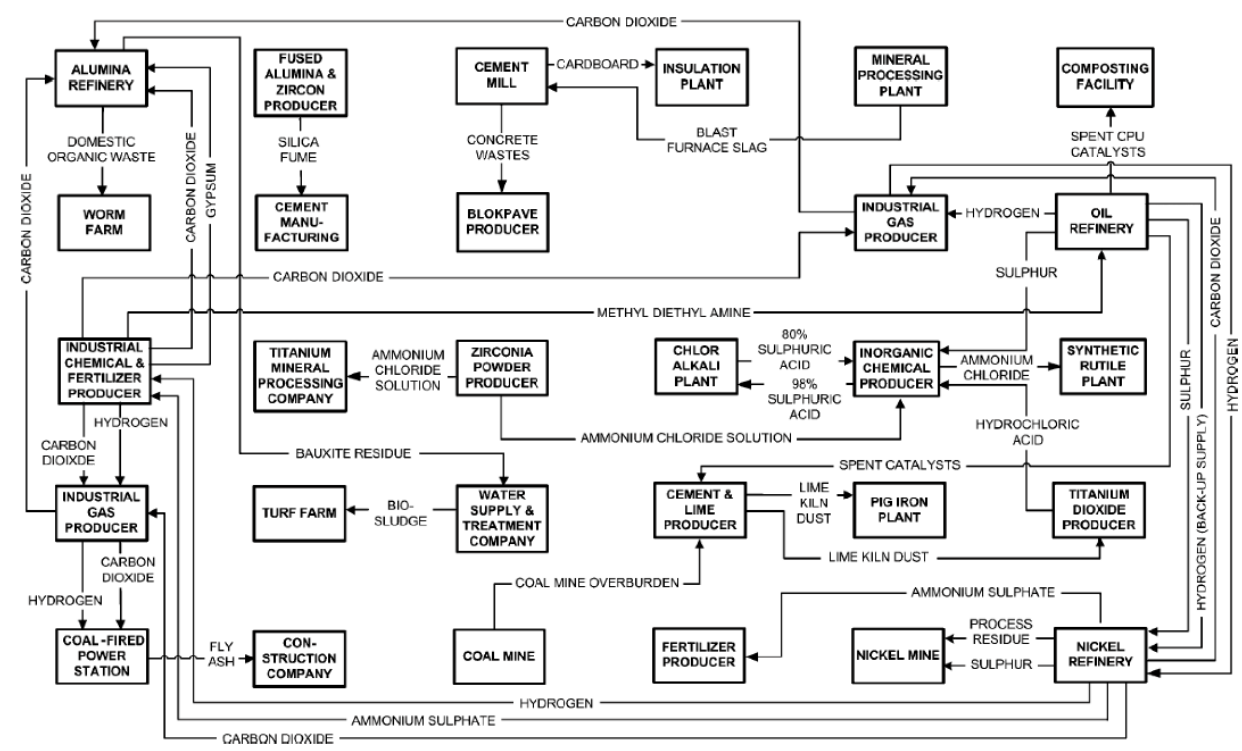

Figure 1.Existing by-product synergies in Kwinana (Beers et al. 2008).

\section{Current methodological advances for EIP design optimization}

The goal of the optimization methodology is to generate optimal EIP network configurations by choosing the number of connections (or links) among the Individual Actors (IA) involved in the EIP, and the quantity of energy and material to exchange through such links, while taking into account the specific operational scenarios. The decisions on number of connections and quantity of energy and material to exchange are guided by the design objectives, e.g., formulated in terms of economic and environmental indicators, the design constraints, e.g., number of connections accepted among Individual Actors (IA), and by taking into account future operational factors, e.g., IA topography and operational conditions.

Recent bibliographical references report progress in multi-objective optimization approaches for EIP design, in terms of water management (Aviso et al. 2010; Aviso 2014; Boix et al. 2012), waste valorisation (Chae et al. 2010), and energy and material flows exchanges (Gu, Yassine, et al. 2013) (Table 2). In addition, some methodologies initially developed for industrial process design and integration can be used to identify optimal synergies in EIP. In this view, (Fazlollahi \& Maréchal 2013; Gerber et al. 2013; Pouransari et al. 2014) are proposing advanced methodologies to identify near-optimal conversion pathways of resources in industrial systems. Ranking the different technological solutions for resources valorisation depending on investment cost for process integration, operating cost and environmental impact of the industrial system, these methodologies provide to the decision-maker a large portfolio of possible near-optimal IS.

Table 2. Classification of design and optimization methodologies, depending on the complexity of the mathematical models and number of objective functions.

\begin{tabular}{|c|c|c|c|c|}
\hline & \multicolumn{3}{|c|}{ Number of objective functions } \\
\hline & & Single & Two & Three \\
\hline 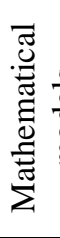 & $\begin{array}{l}\text { Binary variables } \\
\text { indicating } \\
\text { presence/absence the } \\
\text { infrastructure of } \\
\text { between IA and/or flow } \\
\text { rates between IA and/or }\end{array}$ & $\begin{array}{l}\text { - Expenses } \quad \text { for } \\
\text { Resource Purchase for } \\
\text { time period (Chae et al. } \\
2010) \\
-\quad \text { Resource } \\
\text { Consumption } \quad \text { (Aviso }\end{array}$ & $\begin{array}{l}- \text { Quantity of } \\
\text { Exchanged Flows } \\
\text { and Total } \\
\text { Economic Benefit } \\
\text { for time period } \\
(\mathrm{Gu}, \text { Estel, et al. }\end{array}$ & $\begin{array}{l}\text { - Resource Consumption, } \\
\text { Quantity of Resource } \\
\text { Reused and Number of } \\
\text { Connexions in EIP } \\
\text { network (Boix et al. } \\
2012)^{(2)}\end{array}$ \\
\hline
\end{tabular}




\begin{tabular}{|c|c|c|c|}
\hline $\begin{array}{l}\text { location and number of } \\
\text { intermediate } \\
\text { (additional IA) }\end{array}$ & $\begin{array}{l}\text { 2014) } \\
\text { - Payoff for network } \\
\text { infrastructure (Chew et } \\
\text { al. 2011) } \\
\text { - } 4 \text { Total annual } \\
\text { retrofitted cost of EIP } \\
\text { combining capital and } \\
\text { operation costs (Rubio- } \\
\text { Castro et al. 2012) }\end{array}$ & $\begin{array}{l}2013)^{(3)} \\
-\quad \text { Resource } \\
\text { Consumption and } \\
\text { IA Satisfaction } \\
\text { represented } \quad \text { by } \\
\text { Operating } \quad \text { Cost } \\
(\text { Aviso et al. } \\
2010)^{(1)}\end{array}$ & $\begin{array}{l}\text { - Total Supply Cost and } \\
\text { Relative Risk of } \\
\text { production, } \\
\text { transport/storage/transport, } \\
\text { and Total mitigation Cost } \\
\text { of } \mathrm{CO}_{2} \text { (Han et al. 2013) }^{(3)}\end{array}$ \\
\hline $\begin{array}{l}\text { Type of energy/material } \\
\text { conversion technology, } \\
\text { capacity of the conversion } \\
\text { process, thermodynamic } \\
\text { state, investment cost, } \\
\text { utilization rate and } \\
\text { operation strategy } \\
\text { (constraints for slave } \\
\text { problem) }\end{array}$ & $\begin{array}{l}\text { - Total cost composed } \\
\text { of raw material cost, } \\
\text { investment cost and } \\
\text { operating cost (Kim et } \\
\text { al. 2010) }\end{array}$ & 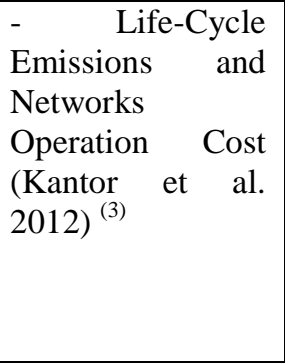 & 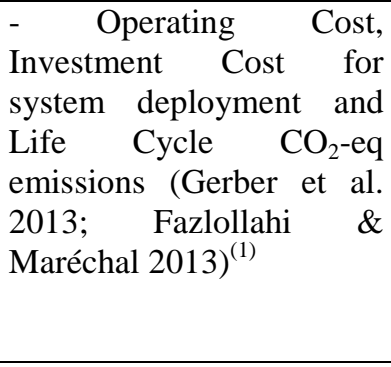 \\
\hline
\end{tabular}

(1) Bi-level optimization problems - leader-slave optimizations

(2) Third objective (number of links/connexions) is considered as an equality constraint

${ }^{(3)}$ Multi-objective weighted optimization

(4) Comparison between several network infrastructures depending of their operational mode through cooperative and non-cooperative games

All methodologies include typical modelling formulations of the optimization problem, such as mass balance, flow rate and quantity to transfer between IA. In some cases, flows quality and topological constraints are also considered, as in (Aviso et al. 2010; Chew et al. 2011). However, the level of details of the industrial system models can vary considerably and the optimization methodologies can be divided into two main categories. A first group includes methodologies where the energy/material process integration problem is formulated as a classical allocation problem in which the presence/absence of infrastructure links among IA, the flow rates between IA and the location and number of intermediate nodes (additional IA) is modelled with binary variables. In the second group the optimization methodologies go into further modelling details of the energy/material transport and conversion technology representation and account for the type of energy/material conversion technology, capacity of the conversion process, thermodynamic state, detailed investment cost of the specific technology, utilization rate and operation strategy.

Finally, from the analysis of the EIP design optimization methodologies, three main problems are identified: the global optimum versus local optimum, the optimization objectives, and the operational uncertainties. These problems are explained below, and for each the approach to undertake the problem is depicted.

- Dominance of the global optimum over the local optimum, i.e., objectives driving the design process are typically formulated at the global level of the EIP system. Almost all decision-making approaches account for the global optimization objectives, without considering the local IA preferences for their interconnections. The exceptions from this are the works by (Aviso et al. 2010; Gerber et al. 2013; Fazlollahi \& Maréchal 2013), which propose performing leader-slave optimization. The slave optimization is solved to satisfy the local objectives and the solutions become constraints for the leader optimization under the global objectives of the EIP controller or other authority. However, these local objectives are mainly related to the technical feasibility objectives and not to the objectives of each IA as an individual intelligent player of EIP. In this 
view, the EIP design process requires more robust 'balancing' of distributed intelligence and desires of IA with global objectives for EIP design. This can be done with the twolevel optimization, where a slave level accounts for IA objectives. By taking into account the fact that EIP can arise spontaneously without central authority guiding the deployment, the EIP design optimization can be inspired from this natural process. Indeed, local optimality can be sequentially considered between pairs of EIP members, to finally derive the optimal EIP configuration (Dickerson et al. 2012; Anderson et al. 2015).

- Limited number of optimization objective falling into the categories of economic and environmental objectives. The optimization approaches from the second category are treating the energy/material integration problem from the point of view of classical energy processes approach. On the one hand, the increased level of details in the mathematical models allows achieving confidence in the feasibility and efficiency of the technology selected based on the optimization results. On the other hand, the complexity of the system representation and of the mathematical approaches selected for this purpose make it almost impossible to explore other aspects in addition to economic and environmental. Despite the modelling complexity decrease in the first category, treating the optimization problem similar to graph optimization (i.e., finding optimal edges between vertexes), the optimization objectives remain economically and environmentally oriented. By considering that IS obtained by interconnection of energy and material producers (suppliers) with consumers, objective functions such as risk for supply shortage must be accounted for during the design phase. Moreover, EIP deployment leads to the creation of multiple networks for energy and material exchanges, for which the performance in terms of network efficiency and vulnerability must be carefully considered during the design phase (Kuznetsova \& Zio 2015).

- Accounting for nominal operational conditions, i.e., EIP design is optimized without considering possible operational uncertainties. For the design optimization process IA, as well as the interconnections among them, are assumed to operate under the nominal conditions. In addition, system weaknesses and failures during operation are not accounted for during the design optimization process. These aspects have only been treated briefly in (Chew et al. 2011), within a cooperative and non-cooperative game setting. The analysis of the existing EIP can reveal EIP networks risks related to the operational conditions uncertainties, IA or interconnections failures and IA shutdowns. This can lead to serious degradation of EIP performance, requiring consequent additional investment to balance the performance degradation. In this view, to design a sustainable and robust EIP network for energy and material exchanges the uncertain operational scenarios must be accounted for at the design phase.

\section{EIP as a complex engineered systems}

This paper claims the need to go beyond classical design approaches, such as those discussed in Section 2, by considering EIP as complex engineered systems. The detailed review of structural and behavioural complexity features of EIP is presented in Appendix A, and complemented here below by the illustration of EIP peculiarities relevant to its complexity.

\subsection{EIP peculiarities}

For ease of illustration, we refer to the example of integration of a heat recovery process between EIP stakeholders (Figure 2a) and in the industrial system (Figure 2b), respectively. 
Figure 2a shows a schematic representation of a symbiotic relation between two EIP stakeholders. For the transformation of raw materials into end products, each stakeholder uses additional inputs in terms of electricity, gas or other raw materials, such as water. The end product fabrication is associated with the auxiliary outputs in terms of energy/material waste. These additional inputs and outputs could be considered as the sinks and sources of energy and materials, respectively.

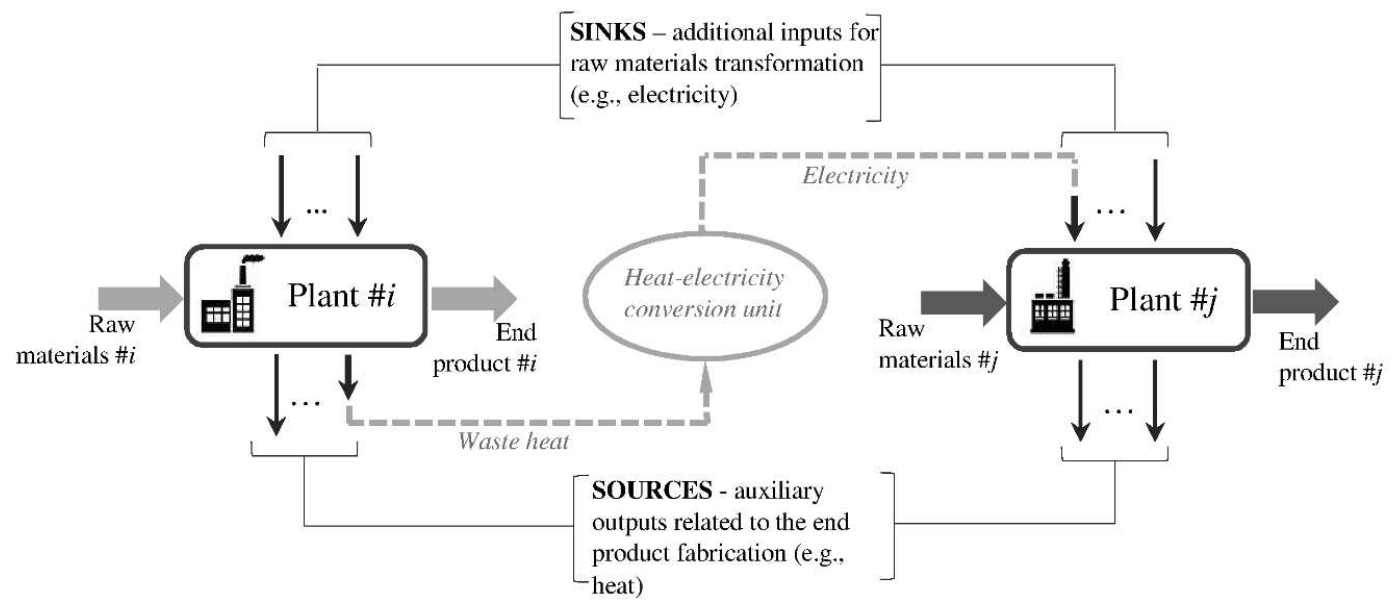

a)

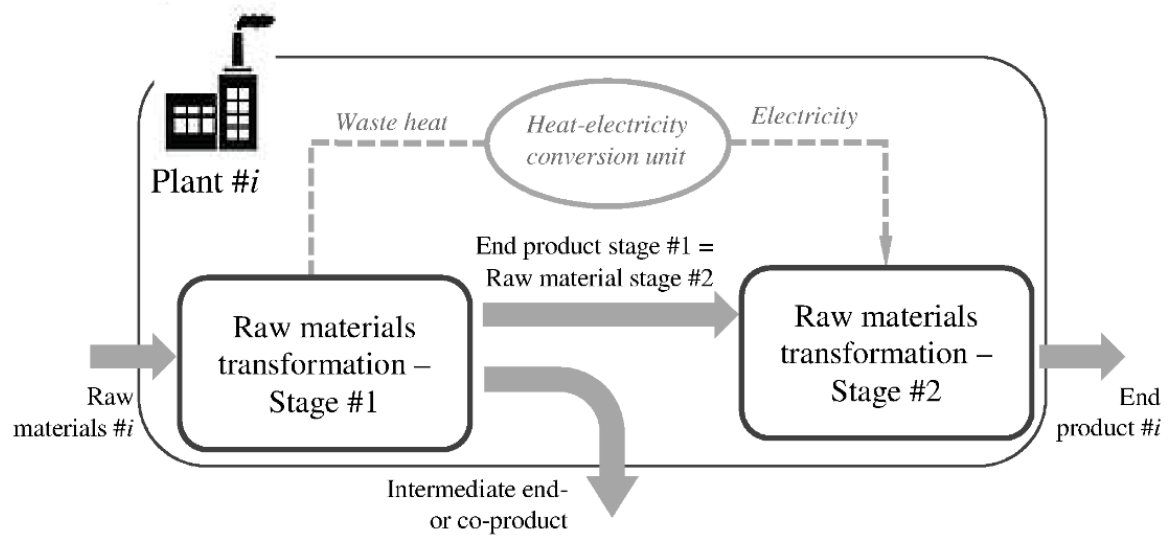

b)

Figure 2. Energy/material conversion process integration: a) between two EIP stakeholders (IS among two plants) and $b$ ) in the industrial plant.

\subsubsection{Business core differences}

Energy/material process integration in EIP can be done between different plants/manufacturers, characterized by different business cores implying different production cycles, raw materials, auxiliary inputs and outputs, security and reliability requirements etc. In classical industrial processes within one or several industrial plants of the same business core, the production cycles and, as a consequence, all related parameters and requirements are under a common denominator and this simplifies considerably the design, integration and dynamic management of energy/material valorisation processes.

Indeed, a parallel can be drawn between EIP and complex industrial plants, integrating several, almost independent units, which is the case, for example, of plants in the petrochemical and metallurgic sectors. In these classical complex industrial plants, the end 
product from one unit becomes the raw material for other units. In this view, this type of direct energy/materials products exchanges enters in the category of 'business as usual'. In comparison, added value creation of energy/material wastes and by-products exchanges in EIP differs from 'business as usual', i.e., if EIP integrates symbiotic exchanges of water it does not mean that the major activities of IA participating in this exchange are to produce water as an end product or consume it as a raw material: energy/materials exchanged in EIP are mainly collateral products of IA, with minimum or negative economic value in comparison with that of the raw material and end product exchanged in the production process of a complex industrial plant.

\subsubsection{Conflicting objectives}

EIP stakeholders potentially interested in energy/materials exchanges may have conflicting objectives, which can compromise the benefit of the symbiosis. An obvious conflicting objective is related to the consumer (sink) and producer (source) relationship, whereby the consumer may aim at decreasing its expenses for energy/material purchase and the producer is aiming at increasing its revenues for energy/material sale. In the existing EIP, this conflict is limited by the application of sale/purchase agreements adopted during energy/materials symbiosis deployment. However, with the development of new EIP and reinforcement of this concept, ground rules for EIP operation can evolve toward market rules as it was the case of electricity grids, whose operation has been upgraded with more advanced electricity trading rules in different countries.

\subsubsection{Additional players}

Another specificity is related to the possible involvement of a third player (company), whose responsibility is to be in charge of operation and maintenance of the infrastructure for energy/material exchanges. Indeed, the additional infrastructure and conversion units built between two EIP stakeholders require specific competences for its operation and maintenance, and the infrastructure operator can take in charge these tasks. The involvement of third players with its own individual objectives introduces additional complexity in terms of long-term dynamic management of energy/material exchanges.

\subsection{Formalizing IS concept for EIP}

Modern principles of industrial system design and operation are emerging by inspiration from biological systems, adapting natural principles to industrial applications (Doyle 2006) and the biological term of "symbiosis" has been assimilated for the engineering systems.

In biology, "symbiosis" can be defined as a relationship between two types of animals or plants, in which each provides for the other the conditions necessary for its continued existence (Dictionary of Cambridge). In opposite to other biological relationships, such as competition and predation, a symbiotic relationship is mainly based on the collateral interactions between species not related to their main living (food chain) activities, e.g., plants pollination by bees and clownfish living in anemone. In the domain of engineering, until now no attempts were taken to formalize the concept of the industrial symbiotic relationship in EIP as it was done for the biological phenomenon, and IS remains a general term indicating the industrial collaboration of different kinds in EIP to achieve economic, environmental or other benefits. In this view, IS can make reference to various possible collaborations, e.g., starting from the shared use of IA infrastructure and resources (Beers et al. 2008) to creation of 
specific interconnections among IA for energy and material exchanges. These last can be divided into two main categories:

(i) EIP can be created around the specific industrial sector to increase the production activity density in the same geographical area, to diversify the end products portfolio and optimize production chains. The typical example, is the chemical EIP of Ulsan (Behera et al. 2012). The important part of exchanges are represented by the chemical materials representing end- or co-products of one IA and serving raw materials to other IA. These exchanges obey to the classical capitalist model of "business-as-usual" among IA restricted to the territory of EIP and cannot be regarded in the true sense of the word symbiosis. In theory, other exchanges, which are not related to the chemical materials (e.g., waste water and steam) can be compliant with the symbiotic relationship. However, considering the specificity of these EIP built around specific industrial sectors (IA with very similar core businesses and objectives), these wastes recoveries are much closer to the process integration in the classical industrial system that in the EIP (Sections 3.1.1 and 3.1.2).

(ii) EIP can be based on the energy and material exchanges among IA of various core businesses, such as EIP of Kalundborg, based mainly on the exchanges waste and some by-products (Chertow 2008). This type of collaborative exchanges is mainly based on the collateral flows exchanges, which is more compliant with the classical biological definition of symbiosis.

The industrial flows can be classified into several categories depending on their value for IA (Horne \& Matthews 2004), i.e., co-product, by-product, waste product and, in some cases, residual products (Figure 3). In this view, co-products involve similar revenues as the main product, by-products result in smaller revenues and waste products provide little or no revenue at all (Horne \& Matthews 2004).

It is natural that collaboration based on co-products are easier to establish. These products usually do not need additional transformation and, as a consequence, additional expenses, and can "find" easily their consumer. However, by taking into account the specificity of these products their consumers will be more likely from the same core business as their producers or this exchange will fall into the category of "business-as-usual". Then, co-products exchanges do not stimulate the diversity of industrial players involved in EIP but facilitate IS creation and management. The boundary between co- and by-product, and by-product and waste can be fuzzy, as their definitions can vary by country or organization. Generally, byproduct is viewed as a low-valued substance, resulting from a production process, the primary aim of which is not the production of that item
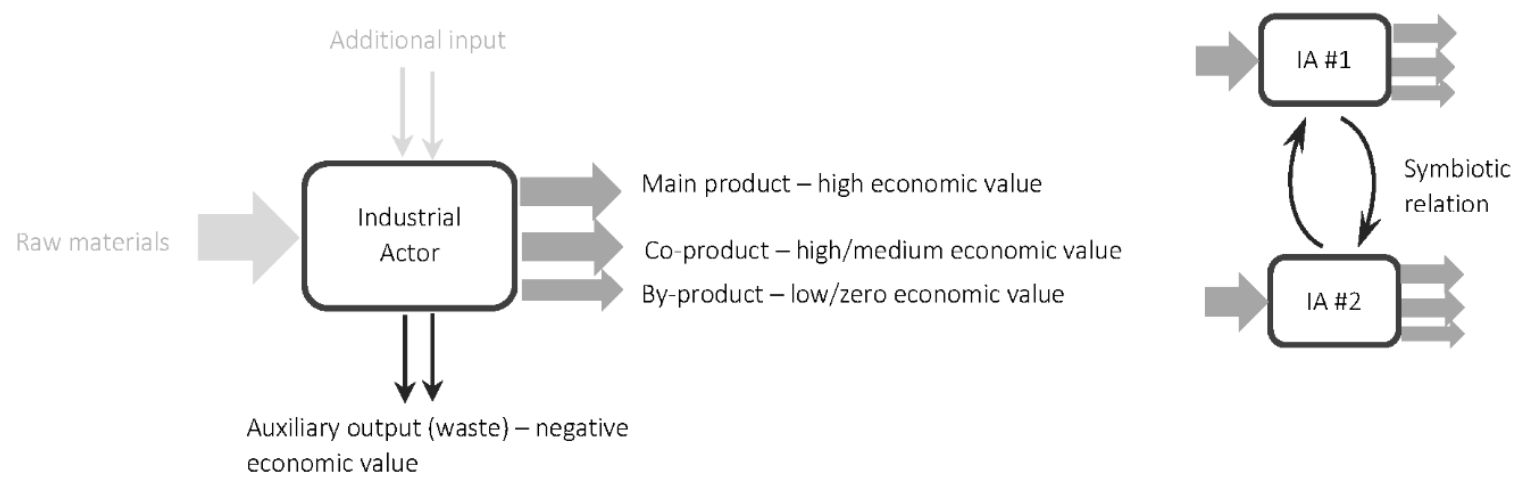

economic value 


\section{Figure 3. IA energy and material flows.}

Note, that by the terms by-products and waste the authors mean currently undervalued energy and materials, such as wasted heat, steam and water. Various hazardous substances which can be emitted during the process of raw material transformation are already the subject of strict control and treatment, and are not considered as the potential products to exchange in EIP.

IS based on waste energy and material recovery, more compliant with the symbiosis concept, may require important economical investment and preparation. Indeed, direct transfer of energy or material wastes from one IA to another IA is not always feasible and may require conversion processes. In this view, the required investment and price of recovered energy and material can be considered by IA as not sufficient to generate payback within an acceptable time period. However, under the pressure of the global environmental challenges the operational conditions can shift in the favour of IS development based on energy and material waste recovery. This supports the analysis done in Section 2, claiming the need of considering future possible direct and indirect incentives to assess the interest for the future development of IS instances.

\subsection{EIP complexity characteristics vs. engineering concepts}

EIP arises by forming networks for energy and material exchange among producers and consumers. To highlight and understand its complexity features, a parallel is drawn with the electricity networks and more specifically the Smart Grids (SG) concept created to improve and optimize the distribution and use of electrical energy. SG are defined as "the information technology backbone that enables widespread penetration of new technologies including cutting-edge advancements in metering, transmission, distribution, and electricity storage technology, as well as providing new information and flexibility to both consumers and providers of electricity" (Hledik 2009). Regarded as complex engineered systems, SG benefited from the development of appropriate engineering concepts for investigation of its complexity characteristics (Table 3). Table 3 also illustrates the attempts done in the field of EIP design and operation.

Main SG design challenges are related to the allocation of the distributed generation technologies in the existing electricity grids. In the absence of network architecture, EIP design challenge is related to the creation of interconnections among the existing energy and material producers and consumers. By accounting for the high IA independence of both SG and EIP systems, further challenges are related to the creation of management and control procedures for reliable operation balancing distributed intelligence with central authority implication.

By looking to EIP and SG similarities in complexity, analysed in details in Appendix A, EIP design optimization practices must evolve toward accounting and integration of different complexity characteristics, such as adaptive learning, evolution and self-organization, to ensure EIP resilience under uncertain operational conditions. This can be partly achieved by addressing the design optimization bottlenecks (Section 2) and by taking into account EIP peculiarities (Section 3.1). 
Table 3. Existent approaches in relation with complex system characteristics and engineering concept.

\begin{tabular}{|c|c|c|c|}
\hline \multirow{2}{*}{$\begin{array}{l}\text { Complex system } \\
\text { characteristic }\end{array}$} & \multirow[t]{2}{*}{ Engineering concept } & \multicolumn{2}{|c|}{ Methodological developments } \\
\hline & & Electricity grids, type of Smart grids & $\begin{array}{l}\text { Interconnected industrial systems, type of Eco- } \\
\text { Industrial Parks }\end{array}$ \\
\hline Architecture & Complex system design & $\begin{array}{l}\text { - Allocation problem - integration of Renewable Energy } \\
\text { Sources into existing grids (Mena et al. 2014) } \\
\text { - Determination of power backup or curtail requested for } \\
\text { electricity grid with high RES penetration (Rodriguez et } \\
\text { al. 2015) }\end{array}$ & $\begin{array}{l}\text { - Complex systems-oriented approaches (simplified } \\
\text { physical models of processes) (Gu, Estel, et al. } \\
\text { 2013; Boix et al. 2012; Aviso 2014) } \\
\text { - Processes integration-oriented approaches } \\
\text { (detailed physical models of processes) (Bansal et } \\
\text { al. 2002; Kim et al. 2010; Gerber et al. 2013) } \\
\text { - Analytical model-based on Agent-Based } \\
\text { Modelling and game theory to transform classical } \\
\text { industrial park into EIP (Romero \& Ruiz 2014) }\end{array}$ \\
\hline Self-similarity & $\begin{array}{l}\text { Structural and behavioural self-similarities } \\
\text { of complex system and its reduced-size copy }\end{array}$ & $\begin{array}{l}\text { - Exploiting of micro grids specificity to test various } \\
\text { energy management techniques in connected and } \\
\text { islanding mode (Chaouachi et al. 2013; Zamora \& } \\
\text { Srivastava 2010; Gabbar \& Abdelsalam 2014) } \\
\text { - Micro grids as a way to contribute to electricity grids } \\
\text { structural and behavioural robustness and resilience } \\
\text { (Rivera et al. 2014; Yanine et al. 2014) }\end{array}$ & $\begin{array}{l}\text { - Energy/material process integration at the level of } \\
\text { industrial plant (interconnected industrial units) and } \\
\text { of industrial unit (interconnected processes) (Yoon } \\
\text { et al. 2007; Grossmann et al. 2014) }\end{array}$ \\
\hline \multirow[t]{2}{*}{$\begin{array}{l}\text { Adaptive } \\
\text { learning }\end{array}$} & Dynamic operation and management & $\begin{array}{l}\text { - Electricity systems management under uncertain } \\
\text { operational conditions (Kuznetsova et al. 2014) }\end{array}$ & - \\
\hline & $\begin{array}{l}\text { 'Soft' flexibility solutions (e.g., demand side } \\
\text { management) - passive control }\end{array}$ & $\begin{array}{l}\text { - Demand-side management solutions (Matallanas et al. } \\
\text { 2012; Kyriakarakos et al. 2013) } \\
\text { - Integration of storage facility and its dynamic } \\
\text { management (Gill et al. 2013) }\end{array}$ & - \\
\hline Evolution & $\begin{array}{l}\text { 'Hard' flexibility solutions (e.g., core } \\
\text { structural and behavioural changes) - active } \\
\text { approach }\end{array}$ & $\begin{array}{l}\text { - Electricity networks enhancement (structural upgrade) } \\
\text { to address Smart grids functionalities - multi-level } \\
\text { network evolution (Pagani \& Aiello 2014) }\end{array}$ & - \\
\hline $\begin{array}{l}\text { Self- } \\
\text { organization }\end{array}$ & $\begin{array}{l}\text { Specific structural and behavioural } \\
\text { techniques allowing 'soft' flexibility and } \\
\text { system protection/recovery }\end{array}$ & $\begin{array}{l}\text { - Analysis of multi-domain barriers and ways } \\
\text { identification for Smart grids implementation (Luthra et } \\
\text { al. 2014) }\end{array}$ & - \\
\hline $\begin{array}{l}\text { Growth } \\
\text { mechanism }\end{array}$ & $\begin{array}{l}\text { Approaches for } \quad \text { sustainable } \\
\text { growth/expansion of industrial system (e.g., } \\
\text { preferential attachment) }\end{array}$ & $\begin{array}{l}\text { - Extension of transmission grids to increase RES } \\
\text { penetration in Europe and US (S. Becker et al. 2014; } \\
\text { Sarah Becker et al. 2014) }\end{array}$ & - \\
\hline Chaos & $\begin{array}{l}\text { Approaches for system protection/recovery } \\
\text { against/after undesirable events repercussion }\end{array}$ & $\begin{array}{l}\text { - Protection techniques against cascading failures } \\
\text { propagation (Zio et al. 2012; Shi \& Liu 2015) }\end{array}$ & - \\
\hline
\end{tabular}




\section{Modelling and optimization methodologies for EIP design}

Based on the previous analysis, this section defines a methodological framework for EIP design. Table 4 presents the elements of the optimization problem elements.

Table 4. Optimization problem for EIP design.

\begin{tabular}{|c|c|}
\hline Optimization problem element & Content \\
\hline Objective function & $\begin{array}{l}\text { - Global EIP objectives (e.g., Investment and Operational Costs, EIP } \\
\text { Network Robustness) } \\
\text { - Local IA objectives (e.g., IA vulnerability) }\end{array}$ \\
\hline Decision variables & Connections among IA (connections capacities) \\
\hline Constraints & $\begin{array}{l}\text { - Number of connections between a pair of IA } \\
\text { - Maximum connection capacity }\end{array}$ \\
\hline Data & $\begin{array}{l}\text { - Topography (IA geographical positions and other geographical factors, } \\
\text { e.g., constructions density, natural and artificial barriers), } \\
\text { - IA operation with sinks/sources variations (e.g., data profiles from } \\
\text { surrogate models or historical data analysis) } \\
\text { - Predictions of operational and environmental conditions (e.g., } \\
\text { operational conditions profiles from models or historical data analysis } \\
\text { and associated risks and uncertainties) }\end{array}$ \\
\hline
\end{tabular}

In addition to the classical optimization problem elements, such as objective function, decision variables and constraints, an important role is played also by the supportive data. This data include some invariant or almost invariant parameters, such as topography, which defines geographical locations and constraints and can be consider as invariant in time, if scenarios of future territorial development are not accounted for in the optimization problem. Other data, such as variations in IA operation and other conditions, require appropriate modelling approaches.

\subsection{IA operation}

For the interconnected industrial systems representation, surrogate or abstract mathematical models which do not account for the detailed physics of energy material conversion processes can be useful for structural analysis. The abstract models help reducing considerably the computational complexity, which is necessary to make robust and solvable optimizations (Tveit 2005; Tveit \& Fogelholm 2006) and making focus on uncertainties and their integration in the optimization framework. In this view, the abstract models can be effectively used to represent not only future EIP nodes or IA (industrial plants and manufactures), but also links or energy/material conversion and transport technologies connecting these IA.

We develop examples of abstract mathematical models representing IA of future EIP. On the one hand, these models must be abstract enough to reduce the complexity of IA and their interconnection. On the other hand, the abstract models must be representative by capturing the major trends in quantities of energy and material sources and sinks of interest for the exchanges through the EIP interconnections.

For this purpose, the internal processes of the IA are not considered and the representation of IA as "black boxes" is considered (Figure 4). Following the IS concept formalization (Section 3.2), these black boxes receive input flows and reject output flow, which can be divided into two groups. The first group are the flows associated with the production/manufacturing process, e.g., in case of coal power plant the input flow is coal and output is electricity. The 
second group includes all additional inputs required for transformation/manufacturing process. In this view, in a coal power plant to transform coal into electricity additional inputs in terms of water and energy are required. In parallel, this transformation process is followed by the auxiliary outputs of gaseous (e.g., GHG emissions), liquid (e.g., wastewater) and solid (e.g., ashes) emissions. The sinks and sources of the second group are the focus of our modelling and optimization for EIP design.

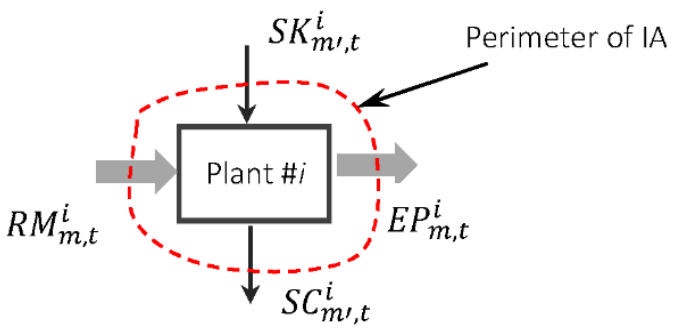

Figure 4. Schematic representation of the IA input and output energy and material flows.

It is evident that the amounts of these sinks and sources are conditioned by the IA operation mode (e.g., type of the end products or 'recipe') and throughput (or production capacity). In this view, the increase of the IA throughput will increase the amount of end product generated/manufactured by the IA which, as a consequence, will require the increase of the demand of additional inputs and will generate more of the auxiliary outputs. The change of the IA operation mode can also modify the amount of required inputs and emitted outputs. For examples in case of Oil Refinery (OR) the operation mode is related to the proportions of the end products such as diesel, gasoline and lube. Each of this end product requires different amounts of the inputs (and generates different amounts and qualities of the outputs) and, thus, the modification of the IA recipe (e.g., prioritizing production of lube over gasoline) will impact the amounts of IA sinks and sources (and in some case the qualities of these sinks and sources).

Based on the above analysis and considering the existing literature on models for different IA, such as OR (Zhang \& Hua 2007) and coal EPP (Mac Dowell \& Shah 2014), the following general formulation for the generic IA operation in the EIP is adopted (Figure 4):

$$
\begin{array}{lr}
E P_{m, t}^{i}=k_{m, t}^{i} E F_{m, t}^{i}=k_{m, t}^{i} R M_{m, t}^{i} & \text { where } E F_{m, t}^{i}=R M_{m, t}^{i}
\end{array}
$$

where $E P_{m, t}^{i}$ and $R M_{m, t}^{i}$ are the amount of the produced end product and consumed raw material, respectively, at time $t, E F_{m, t}^{i}$ is the throughput (or capacity) of IA to produce end product, $k_{m, t}^{i}$ is the production rate of the end product at time $t, S K_{m^{\prime}, t}^{i}$ and $S C_{m^{\prime}, t}^{i}$ are the amounts of additional input and auxiliary outputs, respectively, at time $t$, and $\pi_{m, t}^{i}$ and $\lambda_{m \prime, t}^{i}$ are the coefficients for calculation of additional input and auxiliary outputs at time $t$. Index $m$ denotes the type of raw material or end product, $m \in M$, and index $m^{\prime}$ indicates the type of additional inputs or auxiliary outputs, $m^{\prime} \in M^{\prime}$. Index $i$ is the index of IA within EIP, $i \in N$.

Note that the quantities of energy/material sinks and sources can also depend on the IA operation mode. The additional terms $\psi_{m \prime, t}^{i}$ and $\mu_{m \prime, t}^{i}$ are introduced here similarly to (Zhang 
\& Hua 2007) to reflect the seasonality influence on the additional inputs and auxiliary outputs, e.g., the energy consumption in winter differs from the energy consumption in summer. In (Zhang \& Hua 2007), the values of these additional terms are found by regression form historical data.

By taking into account the different IA inputs and outputs, the revenues which each IA aims to increase are formulated in Eq. 4 below; note that the inventory costs, transport of products, operation mode change cost and shortfall costs are not accounted for:

$R=E P_{e, m, t} \cdot \gamma_{m, t}-E C_{e, m, t} \cdot \vartheta_{m, t}-E D_{e, m \prime, t} \cdot \alpha_{m \prime, t}-E G_{e, m \prime, t} \cdot \beta_{m \prime, t}$

Note that some of additional inputs required for raw material transformation process could be generated/produced locally by IA for its personal use, e.g., oil refinery transfers oil and gas fuel to the utility system which produces low, medium and high pressure steam and generates electricity. In this case of close loop (i.e., no need for the resources from outside for the additional input generation), the price $\alpha_{m, t}$ for additional input purchase can be considered equal to zero.

By using such abstract models for IA, an analysis can be carried out in terms of IA end product demand, which defines the quantities of required and emitted energy and material sinks and sources. In this view, the end product demand and associated prices are usually highly correlated and vary with the seasons. In addition, the proposed abstract models can be easily adopted for dynamic modelling of IA operation within EIP in order to validate efficiency and reliability of EIP symbiosis under dynamically changing operational conditions.

Even if the IA are considered as "black boxes" for the purpose of EIP design, the understanding of their structure and operation is required for the development of their mathematical models and the calibration of the associated parameters, particularly the coefficients quantifying the interdependencies between flows of end products, raw materials, sinks and sources. This is illustrated for the example of OR, providing the information sufficient to parametrize the abstract mathematical model of Eq. 1 - Eq. 3.

The operation of OR supply chain is a complex process depicted in Figure 5a (Behdani et al. 2012; Pitty et al. 2005), where OR occupies a pivotal position initiating and controlling the interactions with the external entities. Various research works focus on the optimization of OR supply chain to increase its benefits (Zhang \& Hua 2007; Mouret et al. 2011). For this paper, we restrict the perimeter of the considered system up to the OR plant controlled by the Operations Department which selects a mode of operation, i.e., recipe, and the throughput of the refinery based on sales. Note that operation mode defines the type of the end products generated by the OR plant.

The simplified configuration of the refinery plant can be divided into process system and utility system (Figure 5b) (Zhang \& Hua 2007). Process system produces the end products, e.g., petroleum gas, gasoline, diesel, and some byproducts, e.g., fuel gas and oil, which are supplied to the utility system as fuel to produce low and medium pressure steam as well as electricity. The generated steam and electricity are used by process system for raw material, i.e., crude oil, transformation. In addition, the refinery complex is usually holding a trade contract with the power grid to balance electricity demand in the whole plant and, in case of electricity surplus generated by the utility system, to sell this electricity surplus to the grid. 
The schematic representation of OR for abstract mathematical model is presented in Figure $5 \mathrm{c}$.

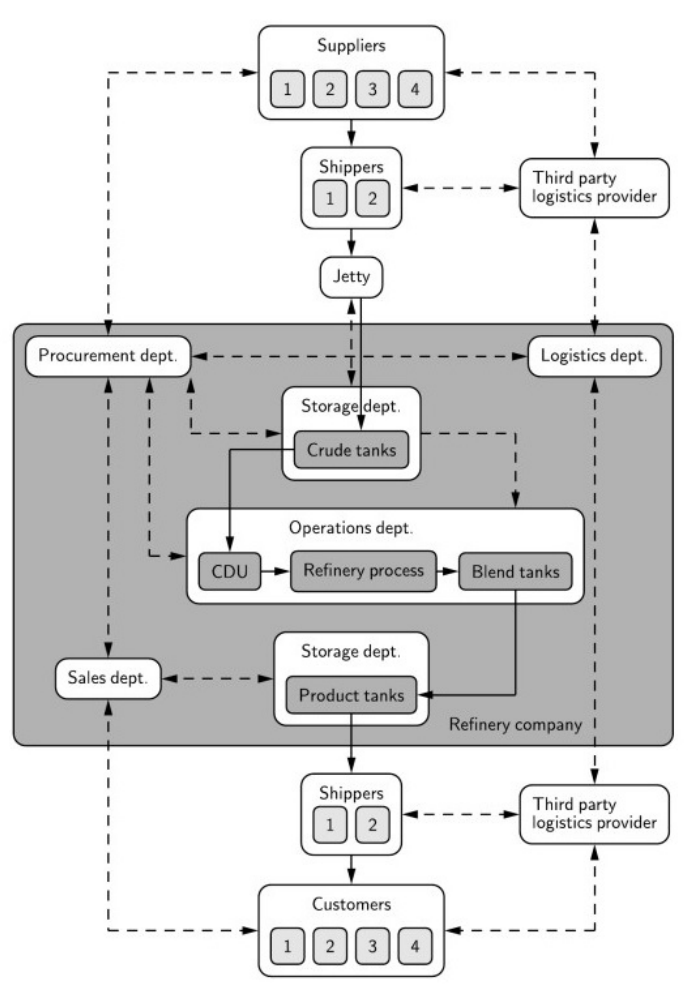

a)

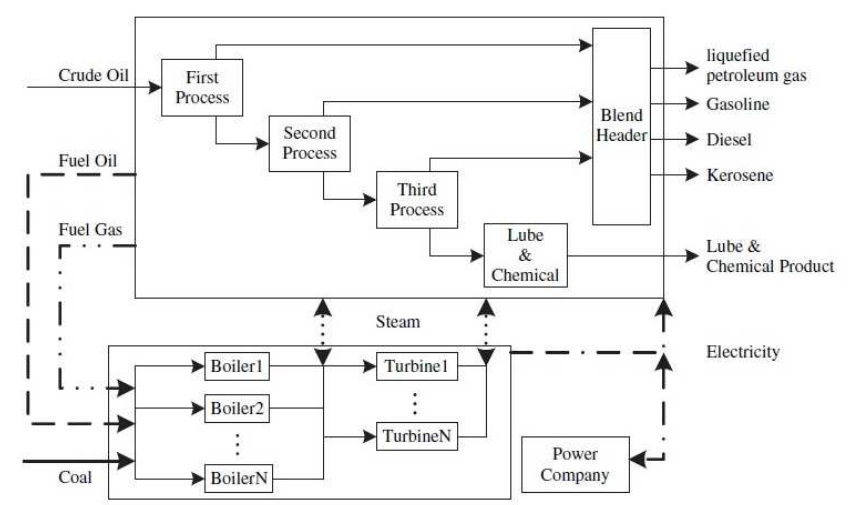

b)

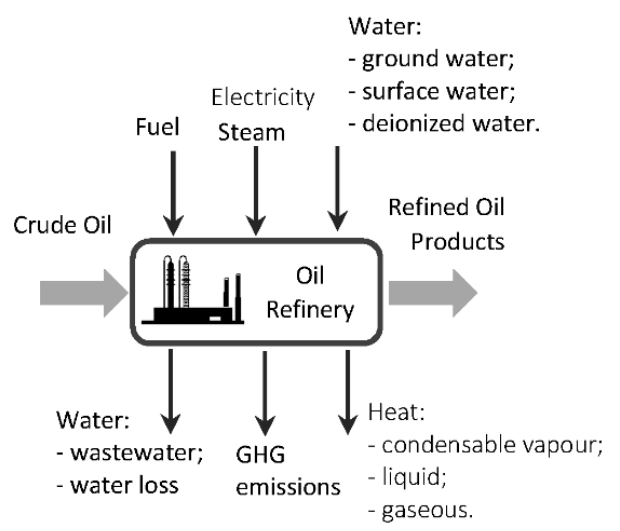

c)

Figure 5. Schematic representation of OR: a) OR supply chain (Behdani et al. 2012), b) simplified configuration of refinery complex (Zhang \& Hua 2007) and c) schematic representation of $\mathrm{OR}$ as an abstract model.

For simplicity, only the refinery system is considered requiring additional inputs for crude oil transformation, e.g., steam, electricity and water, and emitting the auxiliary outputs, e.g., GHG emissions and wasted water. The amounts of these sinks and sources are conditioned by the OR operation mode and throughput, which are decided by the Operation Department based on the end product demand. Note, that the storage of crude oil and end product are not considered here. The variations of these amounts can be estimated by using Eq. 1 - Eq. 3.

To calculate the amount of additional inputs such as fuel, electricity and steam required for the crude oil transformation, the results of mass- and energy-based methods can be used (Wang et al. 2004). Table 5 provides the information on the allocated energy use for the selected end products, i.e., gasoline, diesel and liquefied petrol gas (Wang et al. 2004). The model also provides the amount of GHG emissions associated with different types of the end products.

Table 5. Mass-based process energy allocation by final product for $1 \mathrm{~kg}$ of crude feed and GHG emissions for fuel produced in grams per MJ of fuel available at fuel pump (Wang et al. 2004).

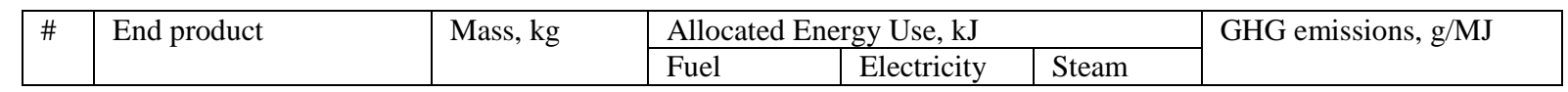




\begin{tabular}{|l|l|l|l|l|l|l|}
\hline 1 & Gasoline & 0.465 & 1345.6 & 53.9 & 183.5 & 19 \\
\hline 2 & Diesel & 0.094 & 146.3 & 9.3 & 39.4 & 14 \\
\hline 3 & Liquefied Petrol Gas & 0.058 & 31.2 & 5.8 & 51.7 & 13 \\
\hline$\ldots$ & $\ldots$ & $\ldots$ & $\ldots$ & $\ldots$ & $\ldots$ & $\ldots$ \\
\hline $\mathrm{N}$ & Total & 1.010 & 2197.8 & 100.7 & 649.4 & - \\
\hline
\end{tabular}

The report of heat recovery opportunities (Frost \& Sullivan 2010) estimated that about $1,145,730 \mathrm{MJ}$ of heat related to the main refinery processes, e.g., distillation, hydro treating and catalytic reforming, is wasted per year. Typically, the wasted heat depends mainly on the amount of allocated energy used to transform crude oil into the end products as well as technical specification of the refinery installations. However, in the absence of the specific information about the coefficient $\lambda_{e, m, t}$ the heat $E G_{e, m, t}$ generated by the refining process is assumed to be constant. The data for wasted heat from different refinery processes can be retrieved from the bibliographical references and classified by type of wasted heat source (Meacher 1981).

Table 6. Waste heat sources in oil refining (Meacher 1981).

\begin{tabular}{|l|l|l|l|l|}
\hline$\#$ & Process & Waste heat source ${ }^{(1)}$ & $\begin{array}{l}\text { Source } \\
\text { Temperature }\end{array}{ }^{\circ} \mathrm{F}$ & $\begin{array}{l}\text { Average Organic Ranking Cycles system } \\
\text { size, } \mathrm{kW}\end{array}$ \\
\hline 1 & Atmospheric Distillation & L\&C & 300 & 1794 \\
\hline 2 & Vacuum Distillation & L\&C & 300 & 1941 \\
\hline 3 & Fluid Catalytic Cracking & L\&C & 300 & 732 \\
\hline 4 & Hydrocracking & L\&C & 295 & 1685 \\
\hline 5 & Hydrogen Plant & G & 300 & 3559 \\
\hline 6 & Catalytic Reforming & L\&C & 280 & 4700 \\
\hline 7 & Hydro treating & L\&C & 250 & 1031 \\
\hline 8 & Hydro refining & L\&C & 250 & 1087 \\
\hline
\end{tabular}

Water plays a key role in OR process, which requires from 200 to $800 l$ of water per tonne of crude oil for the end product generation. In this view, water and energy are intimately connected in a complex relationship of production/consumption in OR when the increase in energy demand will inevitably go hand-in-hand with an increase in demand for water (IFP 2015). Therefore, it is crucial to take into account water sinks and sources and explore the opportunities of their connection into water networks in the context of the EIP.

The water flows into OR plant can be divided into several major categories, such as demineralised water used in boilers, refrigeration water, water used in the desalted unit to reduce the salt content of crude oil before distillation and waste water. Typical sources of water used in the OR are lake, river, ground and sea water. The refinery water balance is schematically depicted in Figure 6, which also accounts for a smaller amount of water entering and leaving the refinery with the crude oil and products, respectively (IPIECA 2010). 


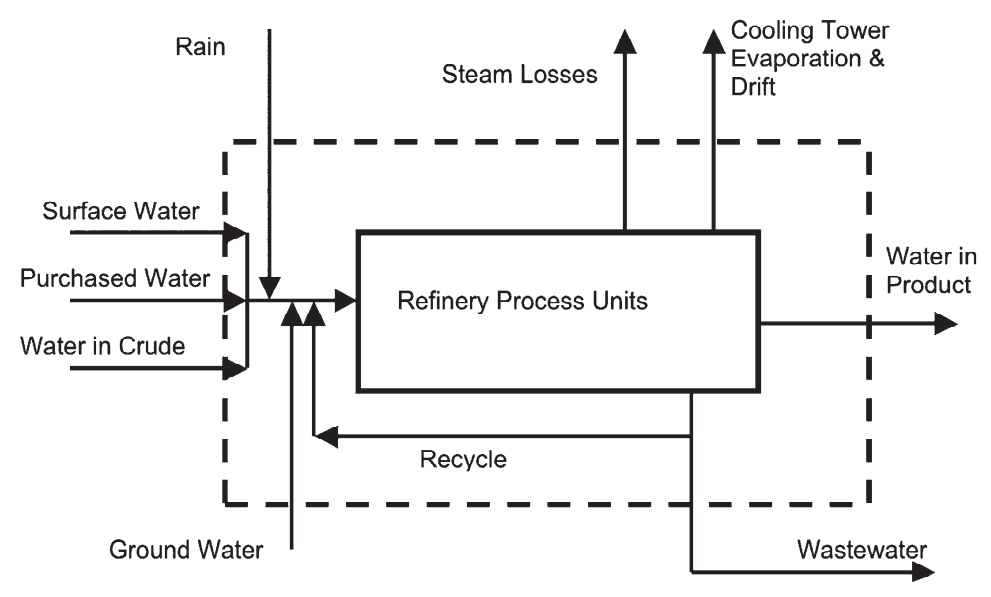

Figure 6. Refinery water balance (IPIECA 2010).

The water use depends on the OR throughputs and operation mode, i.e., recipe of end products. In the absence of the relationship between the OR throughput, operation mode and water sinks and sources, the quantities of required and rejected water can be assumed to be constant and retrieved from the available bibliographical references such as (Mohammadnejad et al. 2011).

Table 7. Water sinks/sources quantities extracted from (Mohammadnejad et al. 2011)

\begin{tabular}{|c|c|c|c|c|}
\hline$\#$ & Water type & Sink or Source & Origin & Quantity, $\mathrm{m}^{3} / \mathrm{h}$ \\
\hline 1 & Boiler blowdown $^{(2)}$ & Sink & Desalter & 14 \\
\hline 2 & Outlet Utility $^{(2)}$ & Sink & Desalter & 45 \\
\hline 3 & Freshwater ${ }^{(2)}$ & Sink & $\begin{array}{l}\text { Cooling } \\
\text { Tower/GC }\end{array}$ & 203.5 \\
\hline 4 & Water Loss & Source & Cooling Tower & 76 \\
\hline 5 & Wastewater & Source & Regeneration & 18.5 \\
\hline 6 & Water Loss & Source & $\mathrm{GC}$ & 8 \\
\hline 7 & Wastewater & Source & GC & 160 \\
\hline
\end{tabular}

Note that the above tables give the crude indications about the amounts for consumed and produced sinks and sources, and can vary depending on OR type and operation mode. In addition, the models of the individual components can be adjusted based on the industrial expertise and data.

\subsection{Prediction of operational and environmental conditions (OEC)}

The identification of potential operational and environmental conditions under which EIP will operate is an important subject. The account of OEC is important in both stages - of EIP design and during EIP operation.

At the one hand, OEC can significantly increase values of IA by-products and waste through the regulation changes requiring the increase of the environmental penalties or stimulating the development of new businesses by added values creation with by-products and waste. In this case, previously underused and underestimated IA sinks and sources will become valuable and must be taken into account at the stage of EIP design. At the other hand, specific OEC or their combination can present some criticalities for EIP. Indeed, as it was mentioned in Section 2, current approaches which can be used for EIP design are optimizing IA interconnections and energy/materials processes integration under expected nominal OEC. 
However, the OEC fluctuations coupled with uncertainties related to IA operational behaviours can generate vulnerabilities for EIP. In this view, the prediction approaches must:

(i) make OEC predictions for the extended horizon (up to EIP lifetime), accounting for the major risks and uncertainties;

(ii) predict OEC for shorter prediction horizon of several months capturing minor EOC fluctuations.

Another challenge is related to the identification of pertinent OEC to take into account at both stages of EIP design and operation. A variety of scenarios representing major future events related to prices and taxes variability and local resources scarcity can be considered, as they can result in a considerable spread of numerical results. Different uncertain factors determine different effects on the operational scenario of the different IA. For example, carbon tax as considerable impact on some IA revenues, which may force them to adopt a range of operational and economic changes in their industrial sector, such as, increase of electricity price in case of energy production. On the contrary, other IA, such as OR, can hold decreased sensitivity to the increase of electricity price since its utility system allows co-generating steam and electricity to be almost self- sufficient under some conditions.

Based on the abstract mathematical model, IA operation can be considerably affected by market demand of end product, i.e., IA output in terms of end products, raw material demand and prices associated with raw material purchase, end product sale as well as for additional inputs and auxiliary outputs. Indeed, the end product demand affects the end product output from the IA and, as a consequence, the sinks and sources associated with AIs end products throughputs. In general, the end product demand varies within lower and upper limits, where the soft lower limit is given by orders booked by sales departments and the hard upper limit is conditioned by the maximum AI capacity (Zhang \& Hua 2007). The potential shortfalls in the end product production can be penalized. However, during the extended operational horizon of EIP lifetime, fluctuations of market demand can considerably exceed the limits of this interval.

On its turn, AIs demand for raw materials including additional inputs (e.g., water, steam) is conditioned by the end product demand. However, the raw materials demand can be constrained by lower and upper limits, where the lower limit defines the minimum purchase amount and the upper limit represents the available amount of the specific raw materials in markets in the given period.

In addition, the end product demand and associated prices are usually highly correlated and vary in to different seasons (Zhang \& Hua 2007). Other OEC can be related to environmental regulation hardening with the increase of environmental taxes, local resources scarcity or partial unavailability and shutdown of IA participating at EIP energy and material exchanges.

\subsection{Industrial system optimization}

According to the analysis done in Section 2, classical optimization methodologies focus mainly on objectives defined for the overall EIP system, e.g., to minimize total investment cost, operating cost or environmental impact. In this view, the objectives of the individual industrial units are not accounted for and the achievement of the overall EIP system goal may result in the detriment of the objectives of some individual enterprises. In this view, the 
optimization approach used for EIP design decision-making must take into account that each industrial enterprise is an individual actor holding its own objectives.

Going further in the IS concept formalization for EIP, the classical formulations of the optimization objectives, such as IA revenues of Eq. 4 of Section 4.1, can be extended to account for the types of interactions which different IA are ready to develop with their neighbours. In this view, EIP can assimilate different types of symbiotic association from biology, such as:

- Mutualism, characterized by the direct or indirect benefit for each IA participating in symbiosis, which allows mutual support for the best fitness to survive under external pressures, and contributes to EIP resilience;

- Commensalism, where, by showing a great structural and behavioural adaptation capacity, a small IA is typically benefiting from a large IA host without harming or benefiting it;

- Parasitism, characterized by the interaction between a large and small IA and leading to the fitness reduction of the host.

The classical rules (followed by the optimization objectives) for EIP design promote the mutualist association among IA. However, it can be assumed that in the future other types of symbiotic associations may be adopted for EIP design. These shifts can be driven by the increase of the external pressures and, more importantly, by the possible redistribution on different OEC. On the contrary, although commensalism association can be adopted under some OEC for EIP design, it is difficult to imagine under which OEC and what kind of IA can allow a parasitism association in the EIP.

In addition, only few works consider risks and uncertainties in the industrial systems design optimization problem. The choice of EIP design is made under certain investment conditions and by considering nominal operational conditions, under which EIP supposes to operate during its lifetime. It is evident, that this assumptions are not realistic and the different risks and uncertainties must be accounted for already at the stage of EIP design.

Another uncertain factor is related to the management and control of energy and materials exchanges in the EIP network. Indeed, as it was highlighted in Section 3.1, EIP network operation differs from the operation of energy/material conversion processes integrated in classical industrial systems, delimited by one or a set of industrial plants of the same holder/core business. In classical industrial processes within one or several industrial plants of the same business core, the production cycles and, as a consequence, all related parameters and requirements are 'brought under the common denominator', which is not the case of EIP. Unfortunately, the specific regulation regarding IA interaction and communication, as well as the organization of energy and material management and control procedures, are not defined. Indeed, energy/materials exchanges in existing EIP are mainly managed in a one-by-one manner, i.e., a pair of IA connected to the infrastructure for energy/materials exchange operates this symbiosis without taking into account the operating strategies adopted by other IA for the exchange of the same energy/materials. Therefore, EIP are usually operating without relying on the particular global coherence. In this view, decisions in one part of EIP, whose consequences can percolate to another EIP part, are communicated and approved at the global level of EIP. This induces additional uncertainties, potentially leading to the situation 
where the optimal EIP network configuration identified at the step of EIP design can manifest some vulnerabilities during EIP operation.

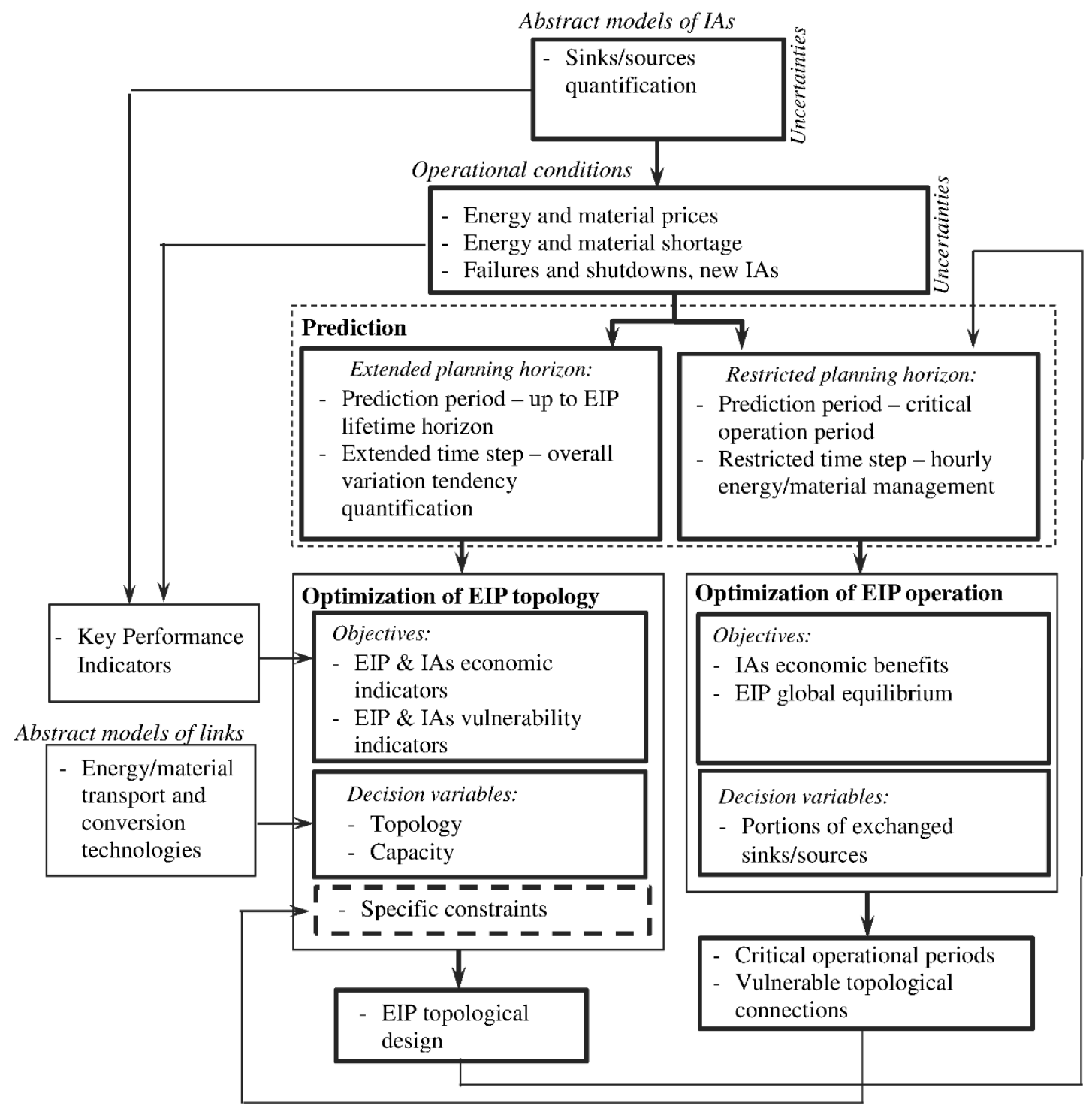

a)

Optimization of EIP topology

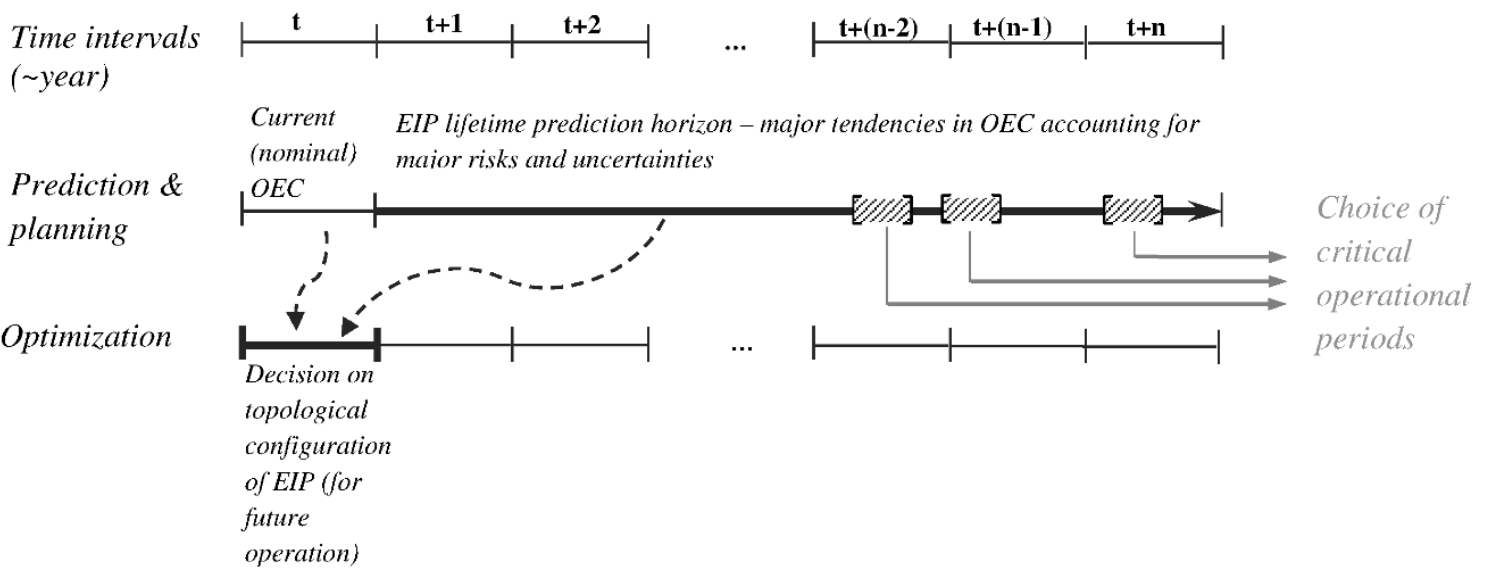




\section{Optimization of EIP operation during critical period}

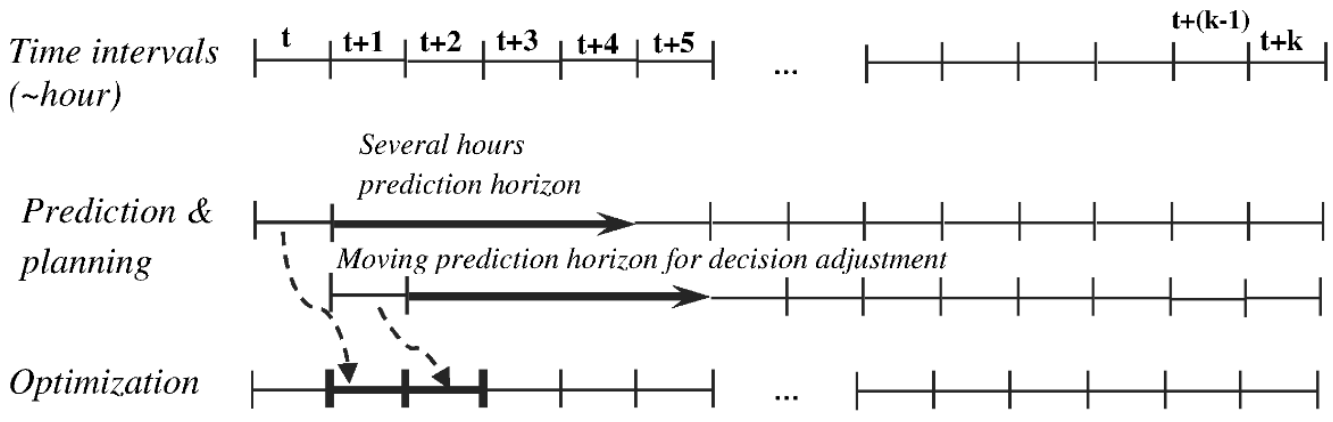

c)

Figure 7. Main stages and interactions of optimization framework for EIP topology and operation: a) Structure of the optimization algorithm; b) EIP design procedure; c) EIP operation procedure.

To address the above bottlenecks, the optimization framework of Figure $7 \mathrm{a}$ a is proposed. As it can be observed, the abstract models of the IA and OEC are used to evaluate Key Performance Indicators (KPI) (Table 8) to guide the objectives of the optimization framework, divided into two parts: (i) the optimization of EIP topology and (ii) the optimization of EIP operation. Each optimization is performed under uncertain operational conditions with different prediction horizons.

Table 8. KPIs for industrial systems evaluation.

\begin{tabular}{|c|c|c|c|c|}
\hline $\begin{array}{l}\text { Industrial } \\
\text { system / } \\
\text { Indicator } \\
\text { category } \\
\end{array}$ & $\begin{array}{l}\text { Economic } \\
\text { performance }\end{array}$ & Environmental performance & $\begin{array}{l}\text { Risk } \\
\text { Exposure }\end{array}$ & Network structural performance \\
\hline IA & $\begin{array}{l}\text { - Economic Profit } P^{i} \\
\text { - Economic } \\
\text { Expenses or } \\
\text { Operating Cost }\end{array}$ & $\begin{array}{l}\text { - Resource Consumption } \\
\text { - Waste generated } \\
\text { - Environmental Impact } E I^{i} \\
\text { (resource + waste) }\end{array}$ & $\begin{array}{l}\text { - Risk for } \\
\text { Supply } \\
\text { Shortage } R^{i}\end{array}$ & $\begin{array}{l}\text { - Impact on Network Connectivity } S \text { (Correa \& } \\
\text { Yusta 2013) }\end{array}$ \\
\hline \multirow[t]{4}{*}{ EIP } & \multirow{3}{*}{$\begin{array}{l}\text { - Economic Profit } \\
P^{E I P} \\
\text { - Economic } \\
\text { Expenses or } \\
\text { Operating Cost } \\
\text { - Investment Cost } \\
\text { for Infrastructure } \\
\text { Construction }\end{array}$} & \multirow{2}{*}{$\begin{array}{l}\text { - Resource Consumption } \\
\text { - Waste generated } \\
\text { - Environmental Impact EI EIP } \\
\text { (resource + waste) } \\
\text { - Quantity of Exchanged Flows } \\
\text { within EIP }\end{array}$} & \multirow[t]{4}{*}{$\begin{array}{l}\text { - Risk for } \\
\text { Supply } \\
\text { Shortage } \\
R^{E I P}\end{array}$} & $\begin{array}{l}\text { - Additional infrastructure construction (Rubio- } \\
\text { Castro et al. 2012) } \\
\text { - Number of EIP connections limitations (Boix et } \\
\text { al. 2012) }\end{array}$ \\
\hline & & & & $\begin{array}{l}\text { - Index of Network Density IND (Romero \& Ruiz } \\
\text { 2014) } \\
\text { - Average Geodesic Distance } \bar{d} \text { (Correa \& Yusta } \\
2013 \text { ) }\end{array}$ \\
\hline & & \multirow{2}{*}{$\begin{array}{l}\text { - Index of Global Environmental } \\
\text { Impact IGEI (Romero \& Ruiz } \\
\text { 2014) } \\
\text { - Index of Global Measurement of } \\
\text { Sustainable Performance IGMSP } \\
\text { (Romero \& Ruiz 2014) }\end{array}$} & & $\begin{array}{l}\text { - Average Network Efficiency } \bar{e} \text { (Correa \& Yusta } \\
\text { 2013) }\end{array}$ \\
\hline & $\begin{array}{l}\text { - Index of Global } \\
\text { Economic Profit } \\
\text { IGEP (Romero \& } \\
\text { Ruiz 2014) }\end{array}$ & & & $\begin{array}{l}\text { - Average Network Vulnerability } \bar{v} \text { (Correa } \& \\
\text { Yusta 2013) } \\
\text { - Contagion Indicator } P_{\text {inf }}(K) \text { (Dodds \& Watts } \\
\text { 2005) } \\
\text { - IAs importance (ranking) } I_{i}, \text { IA load } L_{i} \text { and cost } \\
C_{i} \text {, and critical threshold of avalanche size } T N \\
\text { (Zeng et al. 2013) }\end{array}$ \\
\hline
\end{tabular}

- KPIs used in bibliographical references to optimize EIP design

- Proposed KPIs 
In Table 8 adopted from (Kuznetsova \& Zio 2015) and completed with additional information, KPIs already used in the existing optimization algorithms are highlighted with the grey colour. As it can be observed, these KPIs are related to the global level of the entire EIP system and applied to achieve global optimality of EIP under design mainly in terms of economic and environmental performances. To address the issues of EIP peculiarity and complexity characteristics, the global KPIs have been completed by the additional KPIs providing normalized economic and environmental performances, as well as indicators related to risk exposure and EIP network performance. Following the idea of taking into account the IA preferences regarding EIP deployment, the performance indicators at the IA local level have been integrated. To strengthen the connection between EIP and SG, the additionally proposed network indicators are inspired from metrics used to evaluate electricity grid topological performance (Zio et al. 2012; Correa \& Yusta 2013; Gutfraind 2012).

The optimization of EIP topology is done under the extended planning horizon, which can be extended up to EIP lifetime horizon (up to 40 years) (Figure $7 \mathrm{~b}$ ). This extended horizon accounts for the major risks and uncertainties, which can occur during EIP lifetime, and modelled with the extended time steps from one to several years. In this view, the prediction approaches adopted must be capable of making predictions on future variations of the uncertain parameters (i.e., energy prices) and maximizing the net present value (defined as the difference between total annual revenues and total investment cost, for the entire lifetime of the engineering system) (Hassan \& DeNeufville 2006; Svensson et al. 2011). This optimization is used to identify the topological connections between IA, as well as their capacities.

The optimization of EIP operation is done a posteriori of the topological optimization of EIP when the optimal design or a series of near-optimal designs have been identify and the mathematical model of EIP design is transmitted to the next optimization stage. Period for EIP operation is restricted to short operational periods (of several months duration) (Figure 7c). More specifically these restricted operational periods can represent some critical operational periods preselected at previous optimization step (Figure 7b). The time step selected here can be in the region of several minutes to one hour depending on the type of selected energy and material management procedures. The moving prediction and planning horizon for EIP operation can be adjusted depending on the specificities of IA operation and their operational cycle. The optimization performed at this stage aims at identifying energy and material exchanges between IA. The goal of EIP operation simulation is to identify critical operational periods, e.g., combination of operational conditions, which can lead to stresses in EIP operation and vulnerable IA connections. The identified vulnerabilities are transmitted to the first optimization step of EIP design and converted into specific constraints. This will allow to repeat the step of EIP topological optimization by using the feedback indications aiming to limit future EIP vulnerabilities.

Note that EIP management does not suppose the modification of IA core production processes. Instead, the technological solutions used to connect IA into symbiosis are exploited. In this view, the technological solutions selected to connect different IA at the stage of EIP design phase can integrate particular solutions, such as storage facilities, integrating flexibility into EIP operation. 


\section{Conclusions}

This paper frames the opportunities and challenges of Eco-Industrial Park (EIP) from the point of view of complex systems, by analysing its specificities and by revealing its complexity dimensions. These specificities and complexity aspects must be taken into account for EIP optimal design in terms of performance indicators until now limited to the classical economic and, in some cases, environmental indicators. Comparison with Smart Grids (SG) is made to drive a parallel between engineering concepts for the intelligent allocation and management of distributed generation sources done for SG and concepts aiming at designing and operating complex industrial interconnected systems in the context of EIP. Finally, a specific focus is given on the necessity to account for risks and uncertainties at the level of EIP design in order to identify a reliable and robust EIP configuration.

A two stages EIP design framework has been proposed. Each step includes abstract modelling of Individual Actors (IA), prediction of the Environmental and Operational Conditions (EOC) and optimization of EIP topological design and energy/material management strategy. These two stages are connected by the feedback loop transmitting from the second stage indications about vulnerable operational periods or topological connections at the first stage of EIP topological design. These indications are taken into account in terms of optimization constraints to decrease the impact of future potential risks and vulnerabilities arising during EIP operation. The framework aims at contributing to different stages:

a. We propose to develop abstract mathematical models of IA in order to facilitate due account and propagation of uncertainties. This abstract models can be used to generate scenarios for EIP topological design and also to simulate a dynamic behaviour of IA during the stage of EIP operation optimization. In this view, the EIP optimal design will be no longer identified and validated only by using an universal scenario constituted of statistic data representing nominal conditions. In addition, these abstract models will allow evaluating IA performance depending on different scenarios for EOC.

b. At both stages of EIP design methodology, we propose to use EOC prediction models. At the first stage, the projection into future operational conditions will be done for the extended horizon close to the EIP lifetime. This will allow to switch from the EIP design under nominal conditions toward the design aiming at predicting future variations of the uncertain parameters (i.e., energy prices) and maximizing the net present value of capital investment in EIP construction. Also, the second stage, of EIP operation optimization, is done under the predicted EOC but with shorter prediction horizons. Note, that the use of prediction models instead of known statistical data will allow accounting for possible uncertainties and risks during the optimization stages for robustness of the design and operation solutions.

c. For the first stage optimization of EIP topological design, we propose to push further the concept of parent-slave optimization by taking into account at the slave layer not only some feasibility constraints related to the technological aspects, but the specific objectives and expectations of IA. This will allow to guide EIP topological design, on the one hand, from the point of view of EPI global optimality and, on the other hand, from the point of view of IA local optimality. This aspect becomes particularly important when the development of EIP is driven by one or several most involved IA. The second stage EIP operation optimization is proposed specifically to test EIP behaviour under different uncertain EOC. Indeed, IA interconnections will transform EIP into complex systems, 
whose governance strategy is uncertain (in the absence of specific regulation). In addition, by taking into account EIP specificity an uncertain behaviour of different IA can also considerably affect EIP performance. In this view, a dynamic approach capable of simulating the operation of such system under operational conditions (identify design weaknesses and feedback to the design approach, identify operational weaknesses and test different governance modes) is needed to verify the reliability of the selected EIP topological design. Moreover, the second stage of EIP operation optimization can go further to explore different operational strategies in order to find the optimal one.

Application of the proposed methodology is under development and will be included in the next, more operational, journal paper.

\section{Acknowledgments}

The authors acknowledge PS2E Institute Paris Saclay Energy Efficiency (http://institutps2e.com/) and, in particular, Jean-Paul Gourlia and Romain Farel for their constructive comments to the paper.

The authors also wish to thank the anonymous referees for their scrupulous review work and the comments provided, which have helped improving the paper significantly.

\section{Appendix A. EIP as complex systems}

The appendix provides the analysis of structural and behavioural complexity characteristics of both SG and EIP.

\section{A.1. Structural features}

\section{A.1.1. EIP architecture and IA heterogeneity}

System architecture is the core characteristic defining the topological and/or logic structure linking the elements of the system through their interrelations. System architecture is partly responsible for the system reliable functioning but also for features such as adaptive learning, emergence and evolution to respond to changes in the environment (Nederbragt 1997). A common system architecture is a hierarchical organization, often found in the ecological, taxonomic, genealogical and somatic organization of biological systems to support their adaptive and evolutionary mechanisms in response to changing environmental conditions (Nederbragt 1997).

For example, the SG concept evolves the current architectures of hierarchically-organized trees from production facilities to final consumers towards more decentralized architectures. In particular, microgrid architectures are receiving attention because of the possibility of closer location between generation and consumption sources, which can increase service quality from the consumer's point of view and decrease the transmission losses and the time needed to manage fault restoration and congestions from the producer point of view. In this respect, EIP can be regarded as an attempt to replicate the principles of microgrids, connecting IA of different but comparable-size actors into (micro) networks for energy and material exchanges.

The existing examples of EIP mentioned earlier are built on complex architectures linking heterogeneous IA. As in other complex systems, the specific EIP architecture is partly responsible for the system functional properties and behavioural features, such as adaptive 
learning, emergence and evolution (cf. Section A.2), as emerging through the different IA interactions. Based on the previous analysis of EIP specificities (cf. Section 3.1), these IA can include not only EIP nodes or industrial plants, but also additional players for EIP network operation. In this view, EIP IA are characterized by their strong structural and behavioural heterogeneity. In light of the structural features, this heterogeneity translates in a difference of size and nature of IA.

\section{A.1.2. Self-similarities or fractals}

Generally speaking, complex system architectures tend spontaneously towards fractal structures by fragmentation "into parts, each of which representing (at least approximately) a reduced-size copy of the whole" system (Mandelbrot 1982). In this view, fractals structuring of complex systems implies similar properties at all hierarchical levels and similar complexities at different scales, without a unique characteristic size for their structures. These similarities at different levels of the system are exploited to develop and test different design and operation concepts by using pilot systems as reduced-size copy of the whole system. This concept found wide application in the domains of thermodynamics and fluid mechanics, where developed concepts are tested numerically or on reduced-size experimental tests, whose representativeness of the real-size system is verified with dimensionless numbers, which must be equal for both systems (Bolster et al. 2011).

Practically speaking, SG, for example, tend toward fractal structuring, where fractals at different levels are represented by microgrids including electricity producers, consumers and storage facilities. By the analogy with SG, EIP can benefit from the fractal structuring of complex industrial systems, where the network of interconnected industrial plants can be duplicated by the network of interconnected industrial units inside each plant and by the network of interconnected processes inside each industrial unit, in a nested, fractal architecture.

Fractal structuring can also be exploited in the industrial applications of energy/material processes integration. Indeed, EIP is composed of interconnected IA or industrial enterprises, each of them seen as a set interconnected industrial units and each industrial unit made by the interconnected industrial processes. By taking into account similarities, specific engineering approaches developed at the level of the industrial processes can be transferable and scalable to the level of EIP.

\section{A.2. Behavioural features}

A.2.1. Self-organization, adaptive learning, evolution and growth mechanism

Generally speaking, self-organization, adaptive learning, capability to evolution and growth are the main behavioural properties of complex systems. Self-organization refers to the system capability of adjusting its architectural and behavioural characteristics into a stable coherent pattern under external pressures without intervention of a central authority (NESCI 2005). Adaptive learning uses the mechanism of self-organization, as well as long-term memory experience and anticipate future unfavourable changes in operational conditions or system malfunctioning (NESCI 2005). When the external pressures applied to a system exceed 'critical values' beyond which adaptive learning mechanisms are inefficient, the system is forced to evolve. In the absence of a central authority governing system changes, the evolutionary process resembles natural selection in biological systems resulting in the 
consequent disappearance of elements associated with low adaptive fitness (Kuznetsova et al. 2011). These properties are possible when the IA of the complex system acquire some behavioural autonomy and the complex system is no longer controlled exclusively by a central authority.

Practically speaking, in SG, for example, IA are granted some behavioural autonomy (at the level of decentralized grids). Penetration by decentralized electricity producers, which are no longer obliged to sell the generated electricity to the central grid operator, development of local electricity markets, emerging and reinforcement of new players, such as electricity distributors - all of this contributes to the increase of IA autonomy, which become capable of deciding about their level of demand, production and of negotiating electricity prices without interference from the global grid operator.

EIP can be composed of IA of various core businesses and sizes. Note that the adaptive fitness of different IA can be conditioned by its size or the extent of its core business influence, although it is not necessarily in direct proportionality. Indeed, a small IA is characterized by more agility and less inertia (under the condition of adapting governance strategy) and, thus, greater structural and behavioural adaptation capacity. In opposite, IA of bigger size can be characterized by slower reaction to the external pressures, due to low capability for internal reorganization in a big-size system composed of multiple sub-assemblies. At the same time, this high inertia to change can offer more IA resistance to external pressure. However, when this exceeds a threshold, the IA can collapse and its recovery will require substantial efforts.

EIP involve by default autonomous IA, each one following its own strategy related to the core business. IA are related with each other by interconnections for by-products and waste valorisation, which currently have low economic value and, thus, low importance for IA. Actually, the risk for EIP is that IA possess a surplus of autonomy, which may lead to undesirable behavioural properties as described below.

\section{A.2.2. Feature of chaos}

The term of chaos is used to characterize the capacity of non-linear dynamic systems to produce an unpredictable change in large-scale behaviour or a sudden shift in system pattern, in response to fine-scale changes in initial conditions (Baas 2002). Complex engineered systems are characterized by high sensitivity to changes, which can result in cascading failures propagations within and across systems (Zio \& Aven 2011).

In electricity grids, for example, this chaotic property can be exemplified by system breakdowns often triggered by small perturbations followed by accelerating cascades and large-scale, border-crossing consequences, stressing the importance of (inter)dependencies (Zio \& Aven 2011). Indeed, with the increase of IA local autonomy and development of nontrivial interdependencies, electricity grids respond to perturbations (even small) in ways that are difficult to control.

This chaotic property could be even more critical for EIP. As it was already mentioned in Section 3.1, the strategy of IA within EIP is not to address the demand of other IA in terms of energy/material recovered from their low-valuable sources (waste and by-product), but to achieve their primary core business objectives. In the situation when the operational decision must be made, it is logical to suppose that the main core business strategy will be prioritized at the detriment of EIP objectives. In this view, the repercussions of these decisions on the 
stability and reliability of EIP can be drastic in the absence of some sort of central supervisor for global control.

\section{A.3. Major outcomes}

Based on the analysis provided in this section, the conclusion that can be drawn is that EIP bear some features of complex engineering systems. Table A.1 summarises these complex systems characteristics. Section 3 uses this engineering concept definition to illustrate the methodological concepts developed in case of SG and EIP.

Table A.1. Complex systems characteristics.

\begin{tabular}{|c|c|c|}
\hline $\begin{array}{l}\text { Complex } \\
\text { characteristic }\end{array}$ & Engineering concept & Objectives \\
\hline Architecture & System design and optimization & $\begin{array}{l}\text { Address system design objectives with } \\
\text { minimum investment cost and optimize } \\
\text { expected operational expenses/revenues } \\
\text { under potential uncertainties and risks }\end{array}$ \\
\hline Fractals & $\begin{array}{l}\text { Structural and behavioural self- } \\
\text { similarities of complex system and its } \\
\text { reduced-size copy }\end{array}$ & $\begin{array}{l}\text { Test and validate innovative concepts at } \\
\text { pilot (reduce-size copy) projects }\end{array}$ \\
\hline Adaptive learning & $\begin{array}{l}\text { System dynamic operation } \\
\text { 'Soft' flexibility solutions (e.g., } \\
\text { demand side management) - passive } \\
\text { control }\end{array}$ & $\begin{array}{l}\text { Adapt to the environmental uncertain } \\
\text { conditions fluctuations using self- } \\
\text { organization techniques to optimize } \\
\text { operational expenses/revenues }\end{array}$ \\
\hline Evolution & $\begin{array}{l}\text { 'Hard' flexibility solutions (e.g., core } \\
\text { structural and behavioural changes) - } \\
\text { active approach }\end{array}$ & $\begin{array}{l}\text { "Survive" under major environmental } \\
\text { changes to maintain } \\
\text { expenses/revenues at the acceptable levels }\end{array}$ \\
\hline Self-organization & $\begin{array}{l}\text { Specific structural and behavioural } \\
\text { techniques allowing 'soft' flexibility } \\
\text { and system protection/recovery }\end{array}$ & $\begin{array}{l}\text { Develop intelligent mechanism of structural } \\
\text { and behavioural changes allowing system to } \\
\text { dynamically react in relation to internal or } \\
\text { external changes }\end{array}$ \\
\hline Growth mechanism & 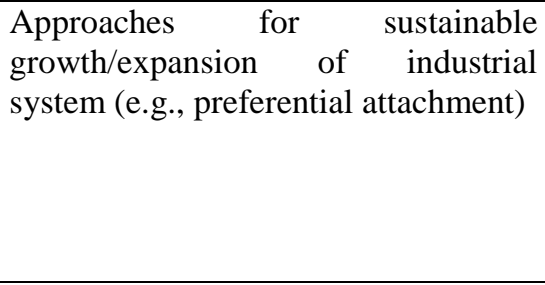 & $\begin{array}{l}\text { Expand (structural growth and increase of } \\
\text { behavioural portfolio) sustainably by } \\
\text { improving system fitness to survive } \\
\text { (strengthen weaknesses), but without driving } \\
\text { it toward extremes, i.e., system 'slow' for } \\
\text { evolution and system favourable to chaotic } \\
\text { behaviour }\end{array}$ \\
\hline Chaos & $\begin{array}{l}\text { Approaches for } \quad \begin{array}{l}\text { system } \\
\text { protection/recovery }\end{array} \text { against/after } \\
\text { undesirable events repercussion }\end{array}$ & $\begin{array}{l}\text { Develop system structural and behavioural } \\
\text { protection mechanisms to withstand major } \\
\text { external risks (system boundary conditions) } \\
\text { and internal risks propagation, and to } \\
\text { automatically restore system up to functional } \\
\text { state }\end{array}$ \\
\hline
\end{tabular}

\section{Bibliography}

Anderson, R., Ashlagi, I., Gamarnik, D. \& Roth, A.E., 2015. Finding long chains in kidney exchange using the traveling salesman problem. Proceedings of the National Academy of Sciences, 112(3). Available at: http://www.pnas.org/content/112/3/663.

Aviso, K.B., 2014. Design of robust water exchange networks for eco-industrial symbiosis. Process Safety and Environmental Protection, 92(2), pp.160-170. 
Aviso, K.B., Tan, R.R., Culaba, A.B. \& Cruz, J.B., 2010. Bi-level fuzzy optimization approach for water exchange in eco-industrial parks. Process Safety and Environmental Protection, 88(1), pp.31-40.

Baas, A.C.W., 2002. Chaos, fractals and self-organization in coastal geomorphology: simulating dune landscapes in vegetated environments. Geomorphology, 48, pp.309328.

Bansal, V., Perkins, J.D. \& Pistikopoulos, E.N., 2002. Flexibility analysis and design using a parametric programming framework. AIChE Journal, 48(12), pp.2851-2868. Available at: http://doi.wiley.com/10.1002/aic.690481213.

Becker, S., Frew, B. a., Andresen, G.B., Zeyer, T., Schramm, S., Greiner, M. \& Jacobson, M.Z., 2014. Features of a fully renewable US electricity system: Optimized mixes of wind and solar PV and transmission grid extensions. Energy, 72, pp.443-458. Available at: http://dx.doi.org/10.1016/j.energy.2014.05.067.

Becker, S., Rodriguez, R. a., Andresen, G.B., Schramm, S. \& Greiner, M., 2014. Transmission grid extensions during the build-up of a fully renewable pan-European electricity supply. Energy, 64, pp.404-418. Available at: http://dx.doi.org/10.1016/j.energy.2013.10.010.

Beers, D., Bossilkov, A., Corder, G. \& Berkel, R., 2008. Industrial Symbiosis in the Australian Minerals Industry: The Cases of Kwinana and Gladstone. Journal of Industrial Ecology, 11(1), pp.55-72.

Beers, D. Van \& Biswas, W.K., 2008. A regional synergy approach to energy recovery: The case of the Kwinana industrial area, Western Australia. Energy Conversion and Management, 49(11), pp.3051-3062.

Behdani, B., van Dam, K.H. \& Lukszo, Z., 2012. Agent-Based Models of Supply Chains. In H. Deguchi, ed. Agent-Based Social Systems. Springer, pp. 151 - 179.

Behera, S.K., Kim, J.-H., Lee, S.-Y., Suh, S. \& Park, H.-S., 2012. Evolution of "designed" industrial symbiosis networks in the Ulsan Eco-industrial Park: "research and development into business" as the enabling framework. Journal of Cleaner Production, 29-30, pp.103-112.

Boix, M., Montastruc, L., Pibouleau, L., Azzaro-Pantel, C. \& Domenech, S., 2012. Industrial water management by multiobjective optimization: from individual to collective solution through eco-industrial parks. Journal of Cleaner Production, 22(1), pp.85-97.

Bolster, D., Hershberger, R.E. \& Donnelly, R.J., 2011. Dynamic similarity, the dimensionless science. Physics Today, 64(September), p.42. Available at: http://scitation.aip.org/content/aip/magazine/physicstoday/article/64/9/10.1063/PT.3.125 8.

Chae, S.H., Kim, S.H., Yoon, S.-G. \& Park, S., 2010. Optimization of a waste heat utilization network in an eco-industrial park. Applied Energy, 87(6), pp.1978-1988. 
Chaouachi, A., Kamel, R.M., Andoulsi, R. \& Nagasaka, K., 2013. Multiobjective Intelligent Energy Management for a Microgrid. IEEE Transactions on Industrial Electronics, 60(4), pp.1688 - 1699.

Chertow, M., 2004. Industrial symbiosis. Encyclopedia of Energy, 3, pp.407 - 415.

Chertow, M., 2013. Taking Action on Materials: Global Examples of By-Product Synergy. In Presented at US Business Council for Sustainable Development. Available at: http://www.google.fr/url?sa=t\&rct=j\&q=\&esrc=s\&source=web\&cd=11\&ved=0CGUQFj AK\&url=http://usbcsd.org/documents/action2020/Marian Chertow.pptx\&ei=SgMtVZvZD6XOygOoh4HgCg\&usg=AFQjCNETEcQhHV348MwS rxlQZdbKnymMCQ\&sig2=uZyy6Mv0jT7b4Kc4u3vxsA.

Chertow, M.R., 2008. "Uncovering” Industrial Symbiosis. Journal of Industrial Ecology, 11(1), pp.11-30. Available at: http://doi.wiley.com/10.1162/jiec.2007.1110.

Chew, I.M.L., Thillaivarrna, S.L., Tan, R.R. \& Foo, D.C.Y., 2011. Analysis of inter-plant water integration with indirect integration schemes through game theory approach: Pareto optimal solution with interventions. Clean Technologies and Environmental Policy, 13(1), pp.49-62.

Correa, G.J. \& Yusta, J.M., 2013. Grid vulnerability analysis based on scale-free graphs versus power flow models. Electric Power Systems Research, 101, pp.71-79.

Dickerson, J., Procaccia, A. \& Sandholm, T., 2012. Optimizing kidney exchange with transplant chains: theory and reality. Proceedings of the 11th ..., pp.711-718. Available at: http://dl.acm.org/citation.cfm?id=2343798.

Dodds, P.S. \& Watts, D.J., 2005. A generalized model of social and biological contagion. Journal of theoretical biology, 232(4), pp.587-604.

Domenech, T. \& Davies, M., 2011. Structure and morphology of industrial symbiosis networks: The case of Kalundborg. Procedia - Social and Behavioral Sciences, 10, pp.79-89. Available at: http://dx.doi.org/10.1016/j.sbspro.2011.01.011.

Mac Dowell, N. \& Shah, N., 2014. Dynamic modelling and analysis of a coal-fired power plant integrated with a novel split-flow configuration post-combustion $\mathrm{CO} 2$ capture process. International Journal of Greenhouse Gas Control, 27, pp.103-119.

Doyle, J., 2006. Bioinspired Concepts: Unified Theory for Complex Biological and Engineering Systems,

EIA, 2013. International Energy Outlook 2013, Available at: http://www.eia.gov/forecasts/ieo/transportation.cfm.

Fazlollahi, S. \& Maréchal, F., 2013. Multi-objective, multi-period optimization of biomass conversion technologies using evolutionary algorithms and mixed integer linear programming (MILP). Applied Thermal Engineering, 50(2), pp.1504-1513.

Frost \& Sullivan, 2010. Waste Heat Recovery Opportunities in Selected US Industries $\square$, 
Gabbar, H. a. \& Abdelsalam, A. a., 2014. Microgrid energy management in grid-connected and islanding modes based on SVC. Energy Conversion and Management, 86, pp.964972. Available at: http://dx.doi.org/10.1016/j.enconman.2014.06.070.

Gerber, L., Fazlollahi, S. \& Maréchal, F., 2013. A systematic methodology for the environomic design and synthesis of energy systems combining process integration, Life Cycle Assessment and industrial ecology. Computers \& Chemical Engineering, 59, pp.2-16.

Gill, S., Barbour, E., Wilson, I.A.G. \& Infield, D., 2013. Maximising revenue for non-firm distributed wind generation with energy storage in an active management scheme. IET Renewable Power Generation, 7(5), pp.421 - 430.

Grossmann, I.E., Martín, M. \& Yang, L., 2014. Review of optimization models for integrated process water networks and their application to biofuel processes. Current Opinion in Chemical Engineering, 5, pp.101-109. Available at: http://linkinghub.elsevier.com/retrieve/pii/S2211339814000574 [Accessed February 12, 2015].

Gu, C., Estel, L., Yassine, A. \& Leveneur, S., 2013. Multi-Objective Optimization for Industrial Ecology: Design and Optimize Exchange Flows in an Industrial. In Proceedings of the 2013 International Conference on Applied Mathematics and Computational Methods. pp. 109-116.

Gu, C., Yassine, A., Estel, L. \& Leveneur, S., 2013. Modeling and Optimization of Material/Energy Flow Exchanges in an Eco-Industrial Park. Energy Procedia, 36, pp.243-252.

Gutfraind, A., 2012. Optimizing Network Topology for Cascase Resilience. In Handbook of Optimizing in Complex Networks: Communication and Social Networks. pp. 37-60. Available at: http://link.springer.com/10.1007/978-1-4614-0857-4.

Han, J.-H., Ryu, J.-H. \& Lee, I.-B., 2013. Multi-objective optimization design of hydrogen infrastructures simultaneously considering economic cost, safety and $\mathrm{CO} 2$ emission. Chemical Engineering Research and Design, 91(8), pp.1427-1439. Available at: http://linkinghub.elsevier.com/retrieve/pii/S0263876213002013 [Accessed January 12, 2015].

Hassan, R. \& DeNeufville, R., 2006. Design of Engineering Systems Under Uncertainty via Real Options and Heuristic Optimization,

Hledik, R., 2009. How Green Is the Smart Grid? The Electricity Journal, 22(3), pp.29-41.

Horne, R.E. \& Matthews, R., 2004. BIOMITRE Technical Manual,

IFP, 2015. Water in fuel production. Oil production and refining,

IPCC, 2014. CLIMATE CHANGE 2014 Synthesis Report, 
IPIECA, 2010. Petroleum refining water / wastewater use and management, London, England.

Kantor, I., Fowler, M. \& Elkamel, a., 2012. Optimized production of hydrogen in an eco-park network accounting for life-cycle emissions and profit. International Journal of Hydrogen Energy, 37(6), pp.5347-5359. Available at: http://linkinghub.elsevier.com/retrieve/pii/S0360319911020052 [Accessed February 5, 2015].

KIC, 2008. Industry’s Environmental Synergies, Kwinana.

Kim, S.H., Yoon, S.-G., Chae, S.H. \& Park, S., 2010. Economic and environmental optimization of a multi-site utility network for an industrial complex. Journal of environmental management, 91(3), pp.690-705. Available at: http://www.ncbi.nlm.nih.gov/pubmed/19880240 [Accessed January 27, 2015].

Kuznetsova, E., Culver, K. \& Zio, E., 2011. Complexity and vulnerability of Smartgrid systems. In European Safety and Reliability Conference (ESREL 2011). Troyes France, pp. $1-8$.

Kuznetsova, E., Li, Y.-F., Ruiz, C. \& Zio, E., 2014. An integrated framework of agent-based modelling and robust optimization for microgrid energy management. Applied Energy, 129 , pp. $70-88$.

Kuznetsova, E. \& Zio, E., 2015. Development of a Case Study for Eco-Industrial Park Deployment under Uncertainty. In L. Podofillini et al., eds. Safety and Reliability of Complex Engineered Systems. Zurich, Switzeland: Taylor \& Francis Group, London, ISBN 978-1-138-02879-1, pp. 2561-2570.

Kyriakarakos, G., Piromalis, D.D., Dounis, A.I., Arvanitis, K.G. \& Papadakis, G., 2013. Intelligent demand side energy management system for autonomous polygeneration microgrids. Applied Energy, 103, pp.39-51. Available at: http://linkinghub.elsevier.com/retrieve/pii/S0306261912007155 [Accessed September 24, 2013].

Luthra, S., Kumar, S., Kharb, R., Ansari, M.F. \& Shimmi, S.L., 2014. Adoption of smart grid technologies: An analysis of interactions among barriers. Renewable and Sustainable Energy Reviews, 33, pp.554-565. Available at: http://dx.doi.org/10.1016/j.rser.2014.02.030.

Mandelbrot, B.B., 1982. The fractal geometry of nature, W.H. Freeman and Company.

Matallanas, E., Castillo-Cagigal, M., Gutiérrez, a., Monasterio-Huelin, F., Caamaño-Martín, E., Masa, D. \& Jiménez-Leube, J., 2012. Neural network controller for Active DemandSide Management with PV energy in the residential sector. Applied Energy, 91(1), pp.90-97. Available at: http://linkinghub.elsevier.com/retrieve/pii/S0306261911005630 [Accessed September 24, 2013]. 
Meacher, J.S., 1981. Organic Rankine Cycle Systems for Waste Heat Recovery in Refineries and Chemical Process Plants. In Third Industrial Energy technology Conferences Houston. pp. 516-523.

Mena, R., Hennebel, M., Li, Y.-F., Ruiz, C. \& Zio, E., 2014. A Risk-Based Simulation and Multi-Objective Optimization Framework for the Integration of Distributed Renewable Generation and Storage. Renew. and Sustain. Energy Rev., 37, pp.778-793.

Mohammadnejad, S., Bidhendi, G.R.N. \& Mehrdadi, N., 2011. Water pinch analysis in oil refinery using regeneration reuse and recycling consideration. Desalination, 265(1-3), pp.255-265.

Available

at: http://linkinghub.elsevier.com/retrieve/pii/S0011916410005576 [Accessed October 28, 2014].

Mouret, S., Grossmann, I.E. \& Pestiaux, P., 2011. A new Lagrangian decomposition approach applied to the integration of refinery planning and crude-oil scheduling. Computers \& Chemical Engineering, 35(12), pp.2750-2766. Available at: http://linkinghub.elsevier.com/retrieve/pii/S0098135411001165 [Accessed October 21, 2014].

Nederbragt, H., 1997. Hierarchical organization of biological systems and the structure of adaptation in evolution and tumorigenesis. Journal of theoretical biology, 184(2), pp.149-56.

NESCI, 2005. Visualizing complex system science (CSS). New England Complex Systems Institute. Available at: www.necsi.org/projects/mclemens/viscss.html.

OECD, 2010. Eco-Innovation in Industry : Enabling Green Growth,

Pagani, G.A. \& Aiello, M., 2014. Power grid complex network evolutions for the smart grid. Physica A: Statistical Mechanics and its Applications, 396, pp.248-266. Available at: http://dx.doi.org/10.1016/j.physa.2013.11.022.

Pearce, D.W. \& Turner, R.K., 1990. Economics of Natural Resources and the Environment Harvester, Wheatsheaf, London.

Pitty, S.S., Srinivasan, R. \& Karimi, I.A., 2005. A Novel Framework and Tool for Dynamic Simulation of Supply Chains.

Pouransari, N., Bocquenet, G. \& Maréchal, F., 2014. Site-scale process integration and utility optimization with multi-level energy requirement definition. Energy Conversion and Management. Available

at: http://linkinghub.elsevier.com/retrieve/pii/S0196890414001137 [Accessed May 11, 2014].

Rivera, S., Farid, A.M. \& Youcef-toumi, K., 2014. A Multi-Agent System Coordination Approach for Resilient Self-Healing Operation of Multiple Microgrids. In The 9th Carnegie Mellon University-Electricity Conference. 
Rodriguez, R. a., Becker, S. \& Greiner, M., 2015. Cost-optimal design of a simplified, highly renewable pan-European electricity system. Energy, 83, pp.658-668. Available at: http://linkinghub.elsevier.com/retrieve/pii/S0360544215002212.

Romero, E. \& Ruiz, M.C., 2014. Proposal of an agent-based analytical model to convert industrial areas in industrial eco-systems. The Science of the total environment, 468-469, pp.394-405.

Rubio-Castro, E., Ponce-Ortega, J.M., Serna-González, M. \& El-Halwagi, M.M., 2012. Optimal reconfiguration of multi-plant water networks into an eco-industrial park. Computers \& Chemical Engineering, 44, pp.58-83.

Shi, B. \& Liu, J., 2015. Decentralized control and fair load-shedding compensations to prevent cascading failures in a smart grid. International Journal of Electrical Power \& Energy Systems, 67, pp.582-590. Available at: http://dx.doi.org/10.1016/j.ijepes.2014.12.041.

Svensson, E., Strömberg, A.-B. \& Patriksson, M., 2011. A model for optimization of process integration investments under uncertainty. Energy, 36(5), pp.2733-2746. Available at: http://linkinghub.elsevier.com/retrieve/pii/S0360544211000910 [Accessed May 26, 2014].

Tveit, T.M., 2005. Experimental design methods and flowsheet synthesis of energy systems. Applied Thermal Engineering, 25(2-3), pp.283-293.

Tveit, T.M. \& Fogelholm, C.J., 2006. Multi-period steam turbine network optimisation. Part I: Simulation based regression models and an evolutionary algorithm for finding Doptimal designs. Applied Thermal Engineering, 26(10), pp.993-1000.

UN, 2003. Water for People Water for Life. The United Nations World Development Report,

Wang, M., Lee, H. \& Molburg, J., 2004. LCA Case Studies Allocation of Energy Use in Petroleum Refineries to Petroleum Products. Implications for Life-Cycle Energy Use and Emission Inventory of Petroleum Transportation Fuels. International Journal of Life Cycle Assessment, 9(1), pp.34-44.

Wen, Z. \& Meng, X., 2014. Quantitative assessment of industrial symbiosis for the promotion of circular economy: a case study of the printed circuit boards industry in China's Suzhou New District. Journal of Cleaner Production, pp.1-9.

Yanine, F.F., Caballero, F.I., Sauma, E.E. \& Córdova, F.M., 2014. Building sustainable energy systems: Homeostatic control of grid-connected microgrids, as a means to reconcile power supply and energy demand response management. Renewable and Sustainable Energy Reviews, 40, pp.1168-1191. Available at: http://linkinghub.elsevier.com/retrieve/pii/S1364032114006935.

Yoon, S.-G., Lee, J. \& Park, S., 2007. Heat integration analysis for an industrial ethylbenzene plant using pinch analysis. Applied Thermal Engineering, 27(5-6), pp.886-893. Available at: http://linkinghub.elsevier.com/retrieve/pii/S1359431106003048 [Accessed September 30, 2014]. 
Zamora, R. \& Srivastava, A.K., 2010. Controls for microgrids with storage: Review, challenges, and research needs. Renewable and Sustainable Energy Reviews, 14(7), pp.2009-2018.

Available

at: http://linkinghub.elsevier.com/retrieve/pii/S1364032110000742 [Accessed August 14, 2010].

Zeng, Y., Xiao, R. \& Li, X., 2013. Vulnerability Analysis of Symbiosis Networks of Industrial Ecology Parks. Procedia Computer Science, 17, pp.965-972.

Zhang, B.J. \& Hua, B., 2007. Effective MILP model for oil refinery-wide production planning and better energy utilization. Journal of Cleaner Production, 15(5), pp.439-448.

Zio, E. \& Aven, T., 2011. Uncertainties in smart grids behavior and modeling: What are the risks and vulnerabilities? How to analyze them? Energy Policy, 39(10), pp.6308-6320. Available at: http://dx.doi.org/10.1016/j.enpol.2011.07.030.

Zio, E., Golea, L.R. \& Sansavini, G., 2012. Optimizing protections against cascades in network systems: A modified binary differential evolution algorithm. Reliability Engineering and System Safety, 103, pp.72-83. Available at: http://dx.doi.org/10.1016/j.ress.2012.03.007. 